\title{
A computational analysis of local flow for reacting Diesel sprays by means of an Eulerian CFD model
}

\author{
A. Pandal ${ }^{\mathrm{a}, *}$, J.M. García-Oliver ${ }^{\mathrm{b}}$, R. Novella ${ }^{\mathrm{b}}$, J.M. Pastor ${ }^{\mathrm{b}}$ \\ ${ }^{a}$ Departamento de Energía (Área de Mecánica de Fluidos), Universidad de Oviedo, Spain \\ ${ }^{b}$ CMT-Motores Térmicos, Universitat Politècnica de València, Spain
}

\begin{abstract}
An implementation and validation of the coupled $\Sigma-Y$ ADF model is presented in this work for reacting Diesel spray CFD simulations under a RANS turbulence modeling approach. An Approximated Diffusion Flamelet (ADF) model [28] implemented in the OpenFOAM CFD open-source library by Winklinger [65] is fed with the spray description, i.e. mixing formation process, provided by the $\Sigma$-Y Eulerian atomization model [17]. In the present investigation, the Engine Combustion Network Spray A reference configuration is used for validation. Specifically, the model can provide accurate predictions of typical reacting spray metrics, such as the ignition delay and the lift-off length. Moreover, the internal structure is also fairly reproduced in terms of quasi-steady spatial distribution of formaldehyde and $\mathrm{OH}$, related with low and high temperature reactions respectively. Additionally, modeling results have been compared to recent Particle image velocimetry (PIV) measurements [16] under both inert and reacting conditions. Flow response to heat release is quantitatively predicted by the model, both in terms of local velocity increase as well as radial dilation. The model has been used to understand combustion-induced reduction in entrainment, in particular around the lift-off length location. Flow confinement does not seem to influence the global flame behaviour, even though some changes in the local flow hint can be observed when moving from an open to a closed domain.
\end{abstract}

Keywords: Eulerian, Unsteady flamelet model, Combustion modeling, Diesel spray, CFD, OpenFOAM ${ }^{\circledR}$

\footnotetext{
* Corresponding author

Email address: pandaladrian@uniovi.es ()
} 


\section{Introduction}

Environmental regulations and fuel economy requirements have become more restrictive in the last decades all over the world and as a result, recent investigations of modern Diesel engines are highly focused on improving combustion efficiency and decreasing pollutant emissions. In order to accomplish this goal, the understanding of fuel injection process and subsequent fuel-air mixing formation and evaporation is essential because they play a major role in combustion and pollutant formation. Otherwise, the mixture preparation may not be adequate and it could also result in zones with local equivalence ratios that are outside the flammability limits, which could reduce the performance of the engine and increase the emission of air pollutants. But also, a better understanding of the combustion process itself is mandatory.

Experimental measurements have traditionally provided the fundamental knowledge on processes that occur in Diesel sprays. However, current Diesel engines are so sophisticated systems that any kind of improvement requires a really great effort. Fortunately, the advent of computers has created a new branch of scientific and engineering research, namely numerical simulation, which in combination with experimental tools has made advancements in this complicated field of science possible. Computer simulations became therefore an integral part in the design process of combustion systems and they can drastically speed up the design process at reduced costs. Furthermore, simulations can provide additional information about the underlying problem, which may be difficult or even impossible to obtain with experiments, and this allows to study the different complex phenomena (heat transfer, gas dynamics, multi-phase flows, and turbulence-chemistry interactions) and hence increase the understanding of the pivotal processes in combustion $[1,21,26]$.

Nevertheless, as pointed out previously, it is impossible to have accurate combustion and pollutant predictions without the correct simulation of the spray formation process. In this sense, Diesel spray modeling has historically relied on a Lagrangian reference frame for the liquid phase while using an Eulerian reference frame for the gaseous one, i.e. the classical Lagrangiandiscrete droplet method (DDM) approach [12]. However, the DDM method presents some well known drawbacks for dense two-phase flow modeling, which more recent single-fluid Eulerian modeling approaches overcome $[9,66]$. This last kind of models are supported by different experimental findings 
such as those conducted by Siebers $[54,55,56]$, which indicate that under current Diesel injection conditions, turbulent mixing and gas entrainment may be the dominant phenomena with respect to fuel vaporization. Such evidences have also been supported theoretically by Oefelein et al. [5, 35, 36]. Furthermore, comparative analyses of different modeling approaches shown within the Engine Combustion Network [14] indicate that the nearand far field spray development under inert conditions are well captured by those Eulerian models. The evaporation and mixing field, therefore, can be predicted with a high degree of accuracy, without the extensive calibration needed for DDM approaches. Recent successful Eulerian treatments include: $[2,3,4,6,7,9,11,17,22,23,32,33,43,53,59,63,66,67]$.

The previous framework indicates that, the Eulerian single-fluid (homogeneous mixture) diffuse-interface approach should be the most reliable one for the prediction of combustion and emissions, where the fuel-air mixing is a governing process. Therefore, in the present contribution, a $\Sigma-Y$ Eulerian spray model, which has been extensively validated under inert conditions $[9,10,17,38,39,40]$, is coupled with a turbulent combustion model based on the laminar flamelet concept (proposed by Peters for non-premixed turbulent combustion [46]). The whole development has been implemented in the OpenFOAM CFD open source c++ library [64]. Particularly, the Approximated Diffusion Flamelet (ADF) model [28], which was proposed for managing complex chemical mechanisms keeping a low computational cost, has been chosen in this work to generate the laminar flamelet manifolds. This simplification has been extensively validated including non-premixed laboratory flames [27, 29, 31] as well as for Diesel engine applications [57, 58], with satisfactory results. Finally, the turbulence-chemistry interaction is accounted for by means of a presumed PDF approach[34, 49]. A tabulation technique is adopted to store precalculated turbulent flamelet solutions in order to allow the use of detailed chemical mechanisms at reasonable computational cost. The full description of the combustion model can be found in [65].

Following the natural framework for the development of the inert spray within the Engine Combustion Network activities, the coupled model will be used to simulate the so-called standard spray A condition, together with two additional ones. Recent experimental investigations by Garcia-Oliver et al. [16] have analyzed in detail the local flow and flame structure, which make up an ideal environment for the validation of the proposed combustion approach. 


\section{Modeling approach}

\section{1. $\Sigma-Y$ model description}

The $\Sigma$-Y model considers the liquid/gas mixture as a pseudo-fluid with a single velocity field. Under the assumption that the flow exiting the injector is operating at large Reynolds and Weber numbers, it is possible to assume a separation of the large scale flow features, such as mass transport, from the atomization process occurring at smaller scales. This allows the simulation of the large scale bulk transport of the liquid, while unresolved turbulent transport is modelled using standard closures such as those used in Reynoldsaveraged turbulence models.

To track the dispersion of the liquid phase an indicator function is used, taking a value of unity in the liquid phase and zero in the gas phase. The mean liquid volume fraction is denoted $(\bar{Y})$ and the mean mass averaged fraction is defined as $\left(\tilde{Y}=\frac{\overline{\rho Y}}{\bar{\rho}}\right)$. Favre averaging the transport equation for the liquid mass fraction yields Eq. (1)

$$
\frac{\partial \bar{\rho} \tilde{Y}}{\partial t}+\frac{\partial \bar{\rho} \tilde{u}_{i} \tilde{Y}}{\partial x_{i}}=-\frac{\partial \bar{\rho} \widetilde{u_{i}^{\prime} Y^{\prime}}}{\partial x_{i}}-S_{e v a p}
$$

where $u^{\prime}$ denotes the density weighted turbulent fluctuations in velocity and $Y^{\prime}$ denotes turbulent fluctuations in liquid mass fraction and $S_{\text {evap }}$ the evaporation source term. The turbulent diffusion liquid flux term, $\widetilde{u_{i}^{\prime} Y^{\prime}}$, captures the effect of the relative velocity between the two phases [61]. This term is modelled using a standard turbulent gradient flux model, which worked successfully for Diesel spray compared to DNS results, as indicated in [7].

$$
\widetilde{\rho} \widetilde{u_{i}^{\prime} Y^{\prime}}=-\frac{\mu_{t}}{S c} \frac{\partial \tilde{Y}}{\partial x_{i}}
$$

where $\mu_{t}$ is the turbulent viscosity and $S c$ is the Schmidt number which will take the value of 0.9 as in other works $[9,10,17,38]$.

The two phases are assumed to form an immiscible mixture and thus, the mass-averaged value of the indicator function is related to the density by:

$$
\frac{1}{\bar{\rho}}=\frac{\tilde{Y}}{\rho_{l}}+\frac{1-\tilde{Y}}{\rho_{g}}
$$

An equation of state is then assigned to each phase to calculate the corresponding density. The gas phase obeys an ideal gas law, while for the liquid 
phase, density is calculated following the Hankinson-Brobst-Thomson (HBT) correlation [50], in which the liquid density is a function of temperature $(T)$ and pressure $(p)$.

Regarding the energy equation, Eq.(4), the static enthalpy $h$ is considered.

$$
\frac{\partial \bar{\rho} h}{\partial t}+\frac{\partial \bar{\rho} \tilde{u}_{i} h}{\partial x_{i}}-\frac{\partial}{\partial x_{i}}\left(\alpha_{e f f} \frac{\partial h}{\partial x_{i}}\right)=\frac{\partial p}{\partial t}+u_{i} \frac{\partial p}{\partial x_{i}}+\tau_{i j} \frac{\partial u_{j}}{\partial x_{i}}
$$

where $\alpha_{e f f}$ is the effective turbulent thermal diffusivity and $\tau_{i j} \frac{\partial u_{j}}{\partial x_{i}}$ the viscous dissipation.

At the end, the temperature evolution is derived from the transported enthalpy applying a bulk mixture enthalpy equation, under the assumption of local thermodynamic equilibrium:

$$
h(T)=\tilde{Y} \cdot h_{f, l}(T)+\sum \tilde{Y}_{i} \cdot h_{i}(T)
$$

where $h_{f, l}$ and $h_{i}$ denote the enthalpy of the liquid fuel and each of the species in the gas phase, respectively. For the the liquid fuel, the Rowlinson-Bondi equation [50], based upon the principle of corresponding states, is applied, while for the vapour fuel the enthalpy of vaporization $\Delta H_{v}$ is added, as obtained from the corresponding states correlation by Pitzer et al. [47]. For the gas remaining species, enthalpies are derived from the respective specific heat capacities at constant pressure evaluated from 7-coefficients NASA polynomials.

The solution of the preceding equations fully characterizes the large-scale bulk motion of the flow. As a result of the separation of scales, atomization is modelled by solving a transport equation for the evolution of the interphase surface area density $\Sigma$, which is defined as the liquid surface present per unit volume at a given time and spatial position. Following the equation adopted by Vallet and Borghi [60], in which nearly all the models in the literature are based, the subsequent transport equation for $\Sigma$ reads as shown in 6 , which assumes a gradient law closure for the turbulent diffusion flux term.

$$
\frac{\partial \tilde{\Sigma}}{\partial t}+\frac{\partial \tilde{u}_{j} \tilde{\Sigma}}{\partial x_{j}}-\frac{\partial}{\partial x_{j}}\left(D_{\Sigma} \frac{\partial \tilde{\Sigma}}{\partial x_{j}}\right)=C_{\Sigma} \tilde{\Sigma}\left(1-\frac{\tilde{\Sigma}}{\bar{\Sigma}_{e q}}\right)+S_{\Sigma_{\text {evap }}}+S_{\Sigma_{\text {init }}}
$$

where $D_{\Sigma}$ is a suitable diffusion coefficient usually taken as the turbulent viscosity $\left(\nu_{t}\right)$ over a Schmidt number $\left(S c_{\Sigma}\right)$. The $S_{\Sigma_{\text {evap }}}$ term appears because 
of the change in the interphase surface as a result of fuel evaporation and is modelled as in Lebas et al. [23]. $C_{\Sigma}$ is an inverse time scale while $\bar{\Sigma}_{e q}$ is the equilibrium or critical surface density to which the local surface density is driven. Finally, the $S_{\Sigma_{\text {init }}}$ term is a proper initialization source term, which is necessary due to the fact that all the terms involved in the equation are proportional to the interface surface density $(\Sigma)$. A detailed explanation of the terms in Eq.(6) can be found in [37, 40].

Finally, in order to account for the spray evaporation, both an additional transport equation for vapor fuel mass fraction (written in a similar way to the liquid fuel one, Eq.(1)) and also a procedure for calculating the evaporation source term, $S_{\text {evap }}$, have to be added. Further description of these modeling additions together with the numerical implementation of this solver can be found in $[9,10,17,38,39,40]$.

\subsection{Combustion model}

In this section the coupling of the Eulerian spray model with the combustion one is explained. This was already implemented by Winklinger [65] for Lagrangian spray models, and further developed in recent works [8]. As previously introduced, the combustion modeling strategy can be classified as an Unsteady Flamelet/Progress Variable (UFPV) approach, using the ADF model with the aim of decreasing the computational cost of the generation of the flamelet manifolds.

As a basis for the model, a transport equation for the mean mixture fraction $\tilde{Z}$ and the mixture fraction variance $\tilde{Z}^{\prime \prime 2}$ are needed:

$$
\begin{gathered}
\frac{\partial \bar{\rho} \tilde{Z}}{\partial t}+\frac{\partial \bar{\rho} \tilde{u}_{i} \tilde{Z}}{\partial x_{i}}-\frac{\partial}{\partial x_{i}}\left(\frac{\mu_{t}}{S c} \frac{\partial \tilde{Z}}{\partial x_{i}}\right)=S_{\text {evap }} \\
\frac{\partial \bar{\rho} \tilde{Z}^{\prime \prime 2}}{\partial t}+\frac{\partial \bar{\rho} \tilde{u}_{i} \tilde{Z}^{\prime \prime 2}}{\partial x_{i}}-\frac{\partial}{\partial x_{i}}\left(\frac{\mu_{t}}{S c} \frac{\partial \tilde{Z}^{\prime \prime 2}}{\partial x_{i}}\right)=2 \frac{\mu_{t}}{S c}\left(\frac{\partial \tilde{Y}_{v}}{\partial x_{i}}\right)^{2}-\bar{\rho} \tilde{\chi}
\end{gathered}
$$

In the Eq. 8, the mean scalar dissipation rate is modeled as:

$$
\tilde{\chi}=C_{\chi} \frac{\varepsilon}{k} \tilde{Z}^{\prime \prime 2},
$$

where the turbulent dissipation $\varepsilon$ and the turbulent kinetic energy $k$ are directly obtained from the turbulence model. The constant $C_{\chi}$ is calibrated in terms of inert spray measurements, as explained below. 
As the target of the present application is the Engine Combustion Network "Spray A", n-dodecane is the single fuel species. The mechanism proposed by Narayanaswamy et al.[30], which consists of 255 species and 2289 reactions, is used in this work to describe n-dodecane chemistry. Out of the full set of chemical mechanism species, only $\mathrm{CO}, \mathrm{CO}_{2}, \mathrm{C}_{12} \mathrm{H}_{26}, \mathrm{H}, \mathrm{H}_{2} \mathrm{O}, \mathrm{OH}, \mathrm{C}_{2} \mathrm{H}_{2}$ and $\mathrm{CH}_{2} \mathrm{O}$ are transported in the CFD solver by means of an equation of the type of Eq.10.

$$
\frac{\partial \bar{\rho} \tilde{Y}_{i}}{\partial t}+\frac{\partial \bar{\rho} \tilde{u}_{i} \tilde{Y}_{i}}{\partial x_{i}}-\frac{\partial}{\partial x_{i}}\left(\frac{\mu_{t}}{S c} \frac{\partial \tilde{Y}_{i}}{\partial x_{i}}\right)=S_{\text {evap }}+S_{\text {chem }}
$$

where $\tilde{Y}_{i}$ represent the mass fraction of the different species, the term $S_{\text {evap }}$ is the evaporation source term (which is different from zero only for the fuel species, $\left.C_{12} H_{26}\right)$ and the term $S_{\text {chem }}$ is the reacting source term. Additionally, $\mathrm{C}_{7} \mathrm{H}_{14}, \mathrm{H}_{2}, \mathrm{O}_{2}$ represent the reconstructed species responsible for mass conservation, which are obtained from the atomic balance equations:

$$
\begin{aligned}
\tilde{Y}_{O_{2}}= & -\frac{M W_{O_{2}}}{2}\left(\frac{\tilde{Y}_{C O}}{M W_{C O}}+2 \frac{\tilde{Y}_{C_{2}}}{M W_{C O_{2}}}+\frac{Y_{H_{2} O}}{M W_{H_{2} O}}+\frac{\tilde{Y}_{C H_{2} O}}{M W_{C H_{2} O}}\right. \\
& \left.+\frac{\tilde{Y}_{O H}}{M W_{O H}}\right)+Y_{O_{2}}^{0}, \\
\tilde{Y}_{C_{7} H_{14}}= & -\frac{M W_{C_{7} H_{14}}}{7}\left(-12 \frac{\tilde{Y}_{C_{12} H_{26}}^{0}-\tilde{Y}_{C_{12} H_{26}}}{M W_{C_{12} H_{26}}}+\frac{\tilde{Y}_{C H_{2} O}}{M W_{C H_{2} O}}\right. \\
& \left.+2 \frac{\tilde{Y}_{C_{2} H_{2}}}{M W_{C_{2} H_{2}}}+\frac{\tilde{Y}_{C O}}{M W_{C O}}+\frac{\tilde{Y}_{C O_{2}}}{M W_{C O_{2}}}\right), \\
\tilde{Y}_{H_{2}}= & -\frac{M W_{H_{2}}}{2}\left(-24 \frac{\tilde{Y}_{C_{12} H_{26}}^{0}-\tilde{Y}_{C_{12} H_{26}}}{M W_{C_{12} H_{26}}}+14 \frac{\tilde{Y}_{C_{7} H_{14}}}{M W_{C_{7} H_{14}}}\right. \\
& \left.+2 \frac{\tilde{Y}_{H_{2} O}}{M W_{H_{2} O}}+\frac{\tilde{Y}_{H}}{M W_{H}}+2 \frac{\tilde{Y}_{C H_{2} O}}{M W_{C H_{2} O}}+2 \frac{\tilde{Y}_{C_{2} H_{2}}}{M W_{C_{2} H_{2}}}+\frac{\tilde{Y}_{O H}}{M W_{O H}}\right)
\end{aligned}
$$

where $Y_{k}$ and $M W_{k}$ denote the mass fraction and the molar weight of species $k$, and $Y_{k}^{0}$ is the mass fraction of the tracer of species $k$, necessary for the 


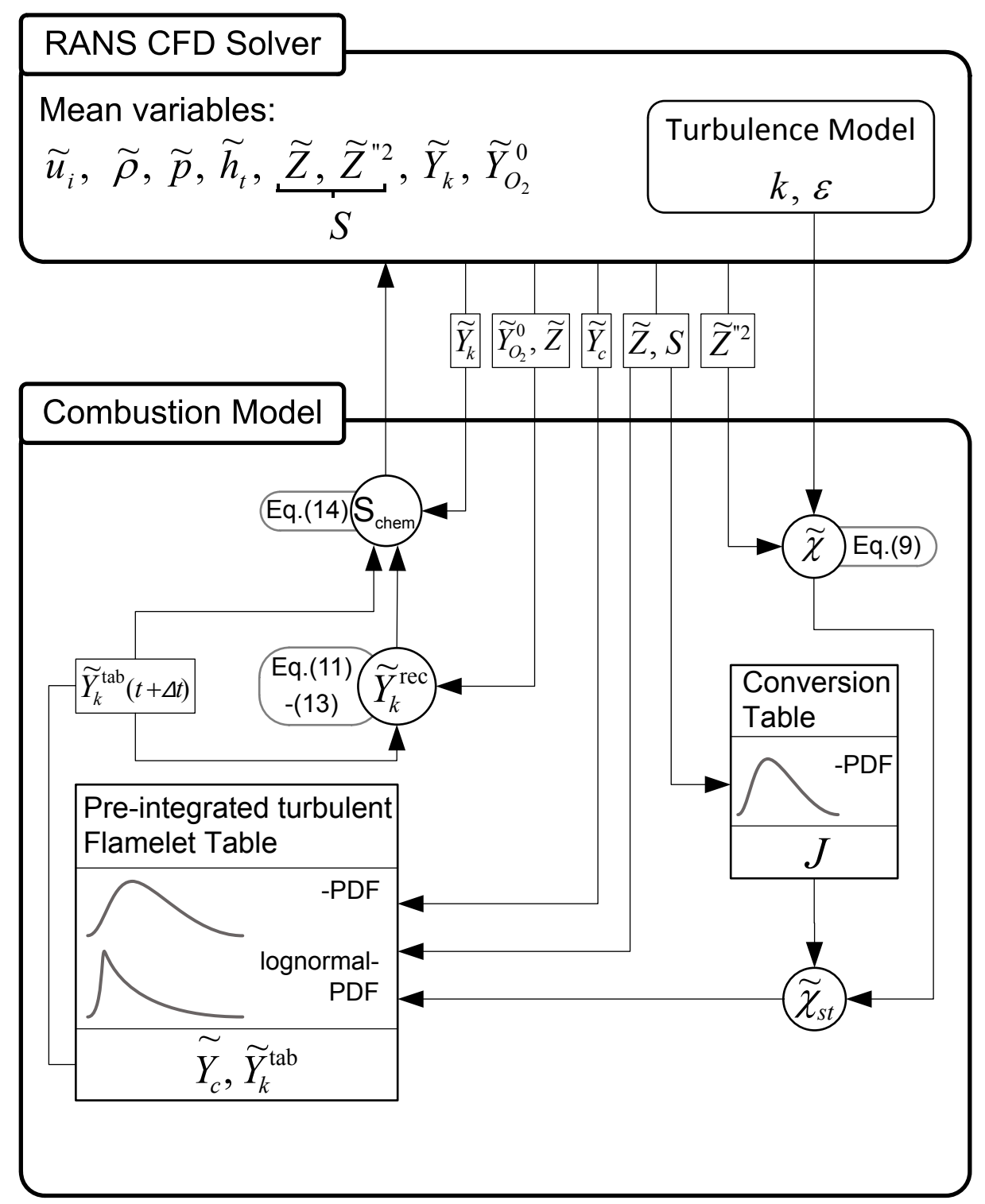

Figure 1: Coupling layout of the combustion model with the CFD code based on species mass fraction tabulation. Adapted from Winklinger [65]

correct balance. Note that the mass fractions of these three species deviate from their real concentration, since they contain contributions from other species that are not considered in the mixture.

The interaction between the CFD solver and the combustion model is 
shown in Fig. 1, adapted from [65]. Here only the main interactions will be reviewed. Mixture fraction average and variance, scalar dissipation rate and $\mathrm{CO}$ and $\mathrm{CO}_{2}$ are retrieved by the combustion model from the corresponding transport equations. Progress variable is then reconstructed as $Y_{c}=Y_{C O}+$ $Y_{\mathrm{CO}_{2}}[8,28]$, which together with a derived stoichiometric scalar dissipation rate enables the calculation of the values of the pre-integrated tabulated species $\tilde{Y}_{k}^{t a b}(t+\Delta t)$ at the subsequent timestep. Finally, these species are combined with those retrieved from the CFD solver $\tilde{Y}_{k}(t)$, so that the source term from the transport equation $\left(S_{\text {chem }}\right)$ is given by Eq. 14 .

$$
S_{\text {chem }}(t)=\frac{\tilde{Y}_{k}^{t a b}(t+\Delta t)-\tilde{Y}_{k}(t)}{\Delta t}
$$

\section{Experimental data}

In order to evaluate and validate the coupled combustion-Eulerian spray model, the ECN Spray A database [14, 20] has been used. The "Spray A" condition consists of a free Diesel spray injected into a quiescent environment, where well-defined boundary conditions and experimental data are available for model validation purposes. The nominal condition for Spray A corresponds to $150 \mathrm{MPa}$ injection pressure, $900 \mathrm{~K}$ ambient temperature and a $22.8 \mathrm{~kg} / \mathrm{m}^{3}$ ambient density.

Table 1: Conditions for Spray A experiments

\begin{tabular}{lccc}
\hline Condition & SA & T2 & EX \\
\hline \hline$P_{\text {inj }}[\mathrm{MPa}]$ & 150 & 150 & 150 \\
\hline$T_{a m b}[\mathrm{~K}]$ & 900 & $\mathbf{7 8 0}$ & $\mathbf{7 8 0}$ \\
\hline$\rho_{a m b}\left[\mathrm{~kg} / \mathrm{m}^{3}\right]$ & 22.8 & 22.8 & $\mathbf{1 4 . 8}$ \\
\hline$X_{\mathrm{O}_{2}}[\%]$ & $15 / 0$ & $15 / 0$ & $15 / 0$ \\
\hline InjDur $[\mathrm{ms}]$ & 1.5 & 5.0 & 5.0 \\
\hline$d_{e q}[\mathrm{~mm}]$ & 0.5 & 0.5 & 0.6206 \\
\hline \hline ID $[\mathrm{ms}]$ & 0.41 & 0.77 & 1.19 \\
\hline LoL $[\mathrm{mm}]$ & 17.1 & 24.6 & 39.5
\end{tabular}

Calculations will be compared to experiments that have been conducted at IFPEN constant-volume pre-burn vessel, which simulates thermodynamic conditions near top-dead-center in a compression-ignition engine [25]. Three 
experimental operating conditions have been considered in the present study, both under inert and reacting conditions, which are described in Table 1 . The first one corresponds to the nominal Engine Combustion Network (ECN) Spray A (SA) condition, starting from which reductions in ambient temperature (T2) and both temperature and density (EX) are performed. Further details about the experimental set-up are provided in [16]. Note that a long injection duration is used for all experiments $(5 \mathrm{~ms})$ to enable the analysis of the steady flow and flame structure, except for the PIV measurements at SA condition, for which the ECN standard 1.5 ms injection duration has been used. Additionally, in Table 1, typical combustion metrics have been shown for these conditions, namely ignition delay (ID) and lift-off length (LoL) used in order to determine the predictive performance of the model.

A single-hole Bosch injector (reference unit \#210678) from the Engine Combustion Network has been used. The fuel is n-dodecane, which has a density of $703 \mathrm{~kg} / \mathrm{m}^{3}$ at the experimental conditions. The fuel pressure is set at $150 \mathrm{MPa}$, for which the steady-state average mass flux through the injector is $2.25 \mathrm{~g} / \mathrm{s}$ and the corresponding momentum flux is $1.22 \mathrm{~N}$, as presented in Table 2 together with the nozzle orifice outlet diameter, the discharge $\left(C_{d}\right)$ and area contraction $\left(C_{a}\right)$ coefficients. Data for the injector reference unit \#210677 have been used for calibration of the scalar dissipation rate model and are therefore also included in the same Table. These injectors are characterized by a smooth entrance and strongly convergent angle, which indicate that the nozzle is unlikely to cavitate, providing a simplification of the nozzle/spray connection. Therefore, only external flow is considered in the present work, even though the internal nozzle geometry may have some impact on near nozzle flow [10].

Table 2: Nozzle characteristics for single-hole Spray A ECN injectors

\begin{tabular}{cccccc}
\hline Injector Serial\# & $D_{o}[\mu \mathrm{m}]$ & $\dot{m}[\mathrm{~g} / \mathrm{s}]$ & $\mathrm{M}[\mathrm{N}]$ & $C_{d}[-]$ & $C_{a}[-]$ \\
\hline \hline 210677 & 83.7 & 2.27 & 1.46 & 0.88 & 0.98 \\
210678 & 88.6 & 2.25 & 1.22 & 0.89 & 0.98 \\
\hline
\end{tabular}

\section{CFD Model set-up}

\subsection{Computational Domain}

In order to simulate the single-hole Spray A injector (Serial\# 210678) external flow, a 2-D axisymmetric computational domain is used corresponding 
to a cylindrical spray chamber $108 \mathrm{~mm}$ in length and $50 \mathrm{~mm}$ in diameter. A structured grid consisting of around 60 thousand hexahedral cells is designed with a similar mesh structure as in $[9,17]$. There are 10 cells along the orifice diameter, keeping an aspect ratio close to one in the near nozzle region (Fig. 2). The non-uniform grid resolution consists of cells with an expansion ratio of 1.01 and 1.06 in the axial and radial directions, respectively.

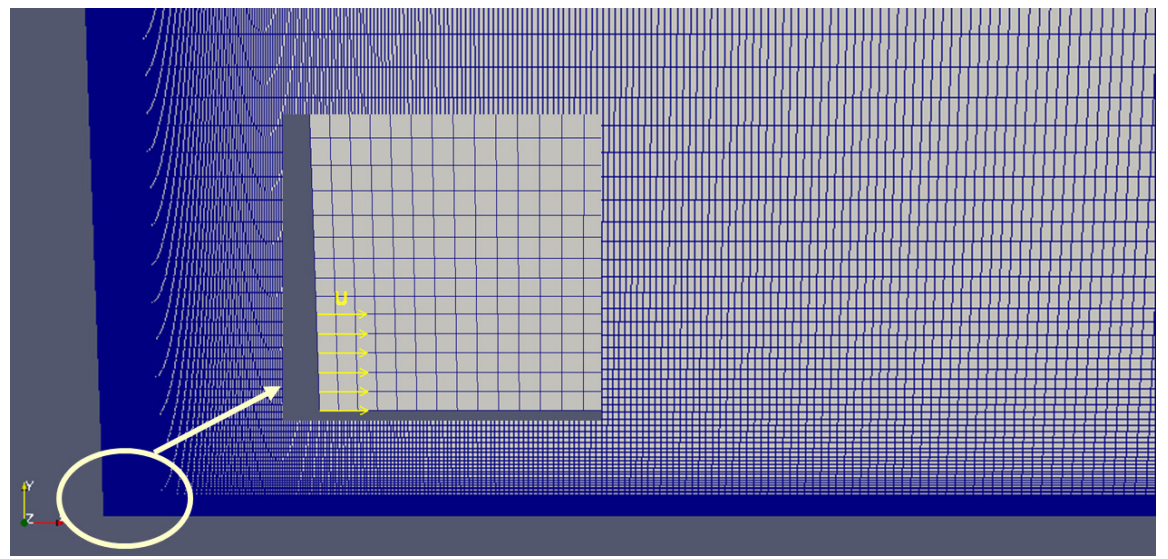

Figure 2: Computational grid for CFD model simulations. The inset shows the mesh near the nozzle exit.

Concerning the boundary conditions, the domain is opened at both the top and final ends of the mesh, while a symmetry boundary condition is chosen for both side planes. No-slip conditions were selected for the wall of the domain, which is located above the inlet. A non-reflective boundary condition is used for the opened outlet and a time varying velocity condition is used for the inlet. The inlet velocity is obtained from mass flow rate and momentum flux measurements [41], applying a constant radial profile of axial velocity and density at nozzle outlet. Additionally, a fully closed mesh (top and final ends) is used to model EX operating condition, both under inert and reacting ambient, in order to check the possible confinement effects, as will be later discussed.

The $\mathrm{k}-\epsilon$ turbulence model was employed for the simulations. Due to the well known round jet spreading overprediction of $\mathrm{k}-\epsilon$ type models [48], a corrected value for $C_{1 \epsilon}=1.60$ is used, as indicated in [9, 10, 17, 38]. Pope [48] has previously suggested that the latter value should be used for round jets. The turbulent intensity was set to $5 \%[9,17,21,26]$ and the length scale to $10 \%$ of the orifice diameter, as suggested in [52]. These values have 
been proved to be quite reasonable after a sensitivity study conducted in [38]. Finally, the discretization of the divergence terms was solved with a Gamma NVD scheme and a first order Euler scheme is applied for time derivative terms.

\subsection{Calibration of the Scalar Dissipation Rate model}

The present setup of the model has enabled accurate predictions of inert spray tip penetration, fuel mass fraction field and quasi-steady liquid length for a large range of ambient gas conditions that are normally present in Diesel engines, as extensively shown in previous work $[9,17]$. Just as an example, Fig. 3 shows the fuel mass fraction along the symmetry axis (left) and the radial distribution at two axial positions, $50 d_{e q}$ and $90 d_{e q}$. CFD predictions are compared against experimental measurements made for nozzle \#210677.
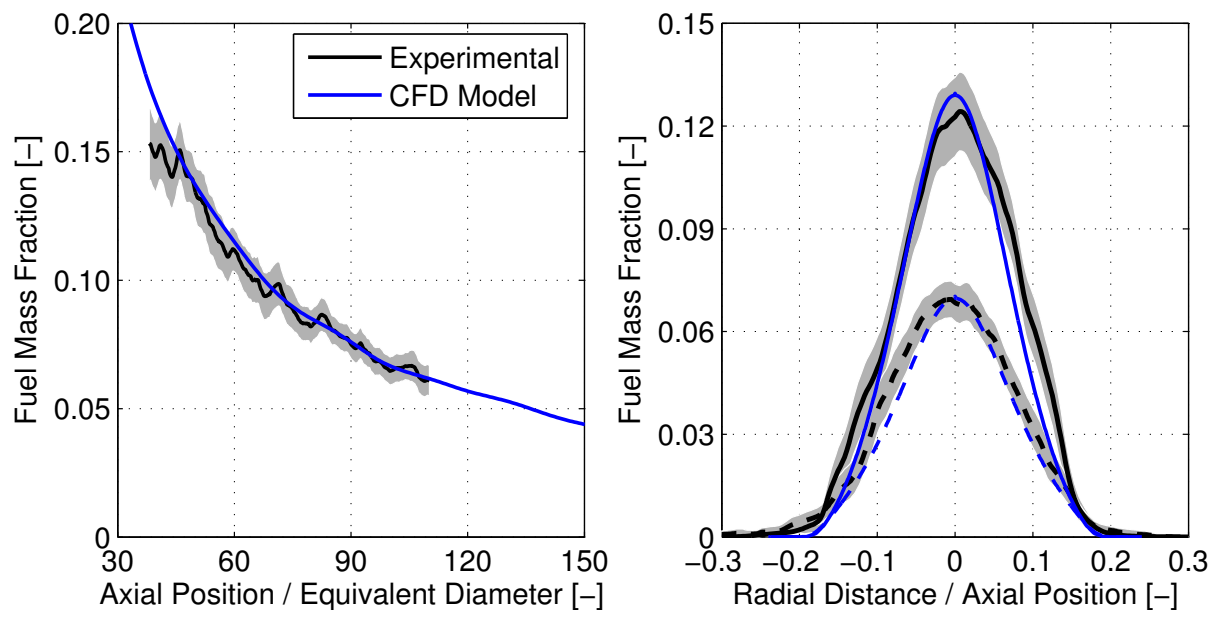

Figure 3: Computed and measured centerline fuel mass fraction [left] and fuel mass fraction radial profiles at $50 d_{e q}$ (solid line) and $90 d_{e q}$ (dashed line) [right] at $2.8 \mathrm{~ms}$ after SOI: Injector 210677, $P_{i n j}=150 \mathrm{MPa}, T_{a m b}=900 \mathrm{~K}$ and $\rho_{a m b}=22.8 \mathrm{~kg} / \mathrm{m}^{3}$

In terms of the combustion model, the mixture fraction variance is a key parameter to quantify the turbulence-chemistry interaction. Experimental measurements of the inert spray mixture fraction variance for the nominal Spray A condition (nozzle \#210677) are compared with modeling predictions to choose a proper value for the modeling parameter $C_{\chi}$. After a calibration process, a value of $C_{\chi}=1.8$ has been chosen.

In Fig. 4, the variance of the mixture fraction is shown along the symmetry axis (left), together with the radial distribution at two axial positions, 

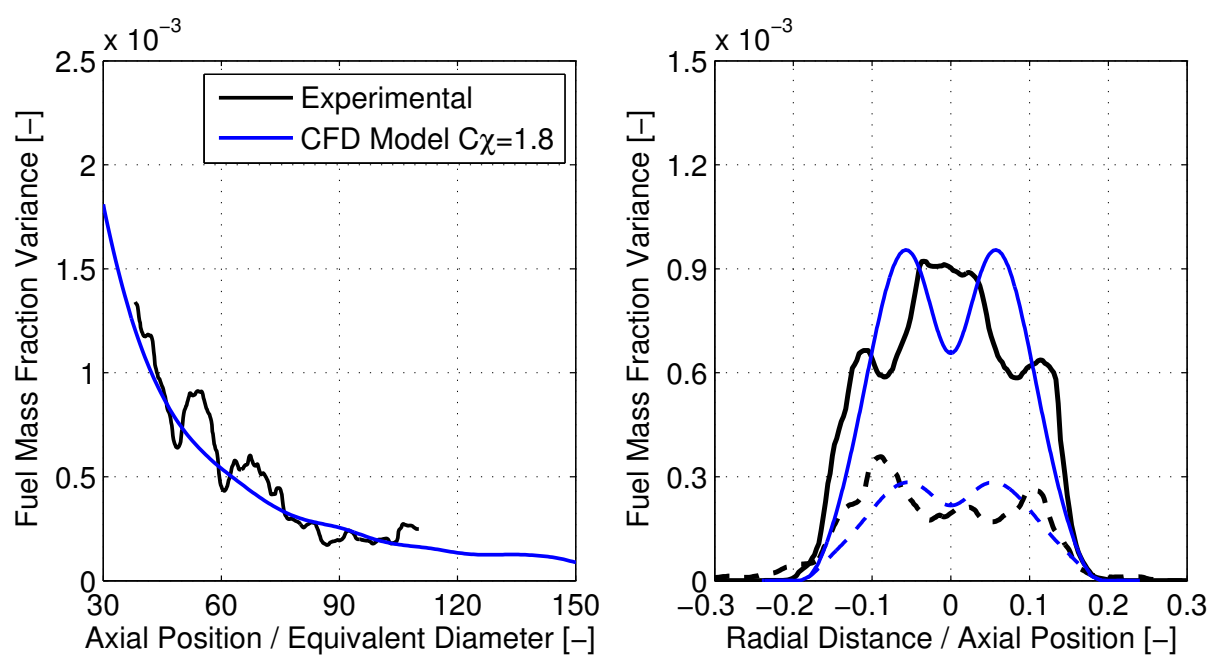

Figure 4: Computed and measured centerline mixture fraction variance [left] and mixture fraction variance radial profiles at $50 d_{e q}$ (solid line) and $90 d_{e q}$ (dashed line) [right] at 2.8 ms after SOI: Injector 210677, $P_{i n j}=150 \mathrm{MPa}, T_{a m b}=900 \mathrm{~K}$ and $\rho_{a m b}=22.8 \mathrm{~kg} / \mathrm{m}^{3}$

$50 d_{e q}$ and $90 d_{e q}$, in a similar way as Fig. 3. Special attention has to be paid to the region closer to the injector, since measured lift-off length values indicate that the inert to reacting transition within the spray occurs at $\left(L o L \simeq 35 d_{e q}\right)$. Selected $C_{\chi}$ constant provides accurate predictions in the lift-off length region, and also a good overall compromise is achieved. In terms of radial profiles, a different shape is provided by simulations compared to measurements. Furthermore, measured profiles show a slight asymmetry, compared to the calculated ones, which are based upon an assumption of axial symmetry. Aside from the previous limitations of shape, one can observe a generally reasonable agreement of the calculated distribution with experimental data for the chosen value of $C_{\chi}$, so the same constant will be used for the modeling of reacting sprays.

\section{Results and Discussion}

In the present section, the model predictions are compared against ECN measurements. First, an analysis of the global combustion parameters and flame structure will be done, to show an overview of the combustion model performance. After that, local flow will be compared to experiments. Finally, entrainment behaviour under reactive conditions will be examined. 


\subsection{Global indicators and flame structure}
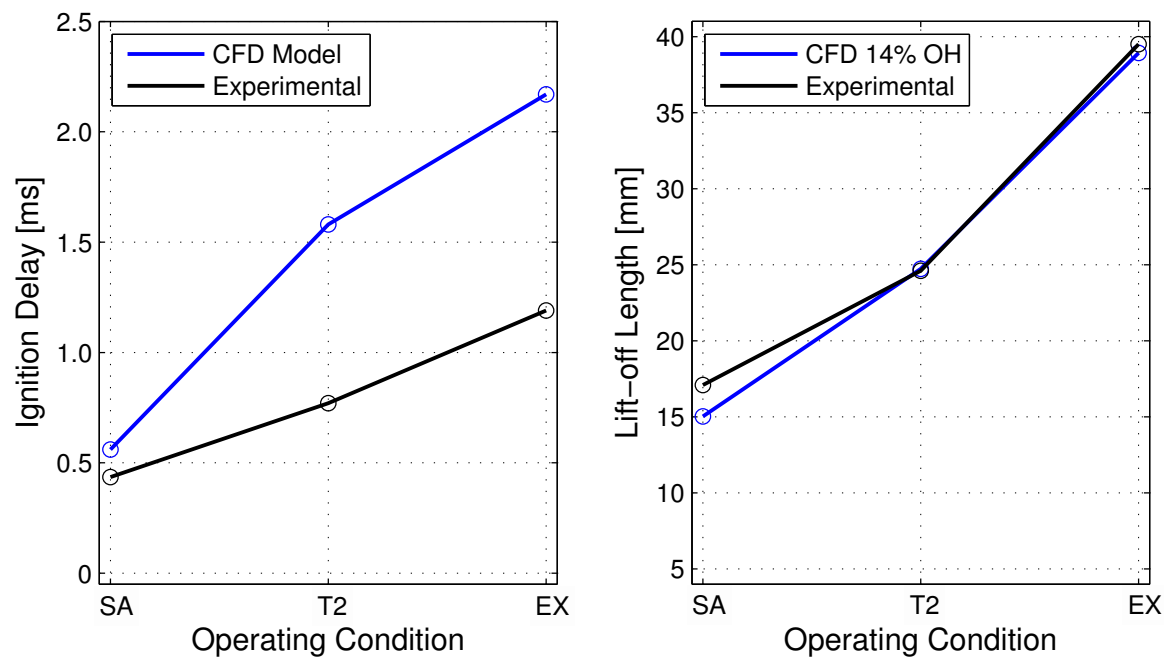

Figure 5: Computed and measured ignition delay (left) and lift-off length position (right) for the different operating conditions. CFD modeling predictions (blue elements) and experimental measurements (black elements)

The two parameters that usually characterize transient reacting Diesel sprays are ignition delay (ID) and lift-off length (LoL). Fig. 5 shows both CFD predictions and experimental measurements of these metrics. Regarding modeling results, ECN [14] recommendations are followed, so that ID is defined as the time spent from start of injection (SOI) until the maximum gradient (dT/dt) in temperature takes place. On the other hand, LoL is defined as the minimum axial distance to the nozzle where $14 \%$ of the maximum value of Favre-average $\mathrm{OH}$ mass fraction in the domain is reached $[8,44]$.

Experimental trends followed by both parameters are well-captured by the model. LoL values deviations from experiments are relatively small for all three conditions, with a maximum difference of around $2 \mathrm{~mm}$ for SA. On the other hand, ID is clearly overpredicted, with deviations being very large for both low temperature conditions, similarly to the literature[8, 45]. This sort of disagreement with experiments has also been observed with the present model [8], and is mainly due to the strong role of chemical mechanism on the exact ignition timing. Other chemical mechanism available [15, 24, 62] should be investigated in the future.

Next, an evaluation of the flame structure provided by the CFD model is made by comparison with PLIF measurements at quasi-steady state in [16] 
(Fig. 6,7 and 8). For each operating condition, experimental measurements are shown at the top. Following the same criteria as in [16], red indicates zones where $\mathrm{OH}$ is detected by the PLIF technique, while green corresponds to regions where PLIF $355 \mathrm{~nm}$ provides signal, due either to formaldehyde $\left(\mathrm{CH}_{2} \mathrm{O}\right)$ or to polycyclic aromatic hydrocarbons (PAHs). For $355 \mathrm{~nm}$ PLIF, the extent of the laser sheet is $0-55 \mathrm{~mm}$ from the nozzle. For OH PLIF, the axial extent of the laser sheet is $40 \mathrm{~mm}$, starting at $20 \mathrm{~mm}\left(40 d_{e q}\right)$ (SA and $\mathrm{T} 2)$ and $40 \mathrm{~mm}\left(64 d_{e q}\right)(\mathrm{EX})$ from the nozzle. Finally, the white solid line is the contour of the $\mathrm{OH}^{*}$ image. On the other hand, CFD results are presented at the bottom with a similar layout. In this case, green color scales linearly with formaldehyde mass fraction, and red color with $\mathrm{OH}$ mass fraction. Because of the absence of the $\mathrm{OH}^{*}$ specie in the combustion mechanism, the white solid line is defined in terms of the limit of the $\mathrm{OH}$ mass fraction. Finally, a white dashed line is shown both on experimental and modeling results corresponding to the stoichiometric isolines from CFD calculations, to have a spatial reference enabling easy comparison between both maps.

For SA condition, formaldehyde location is reasonably captured by the

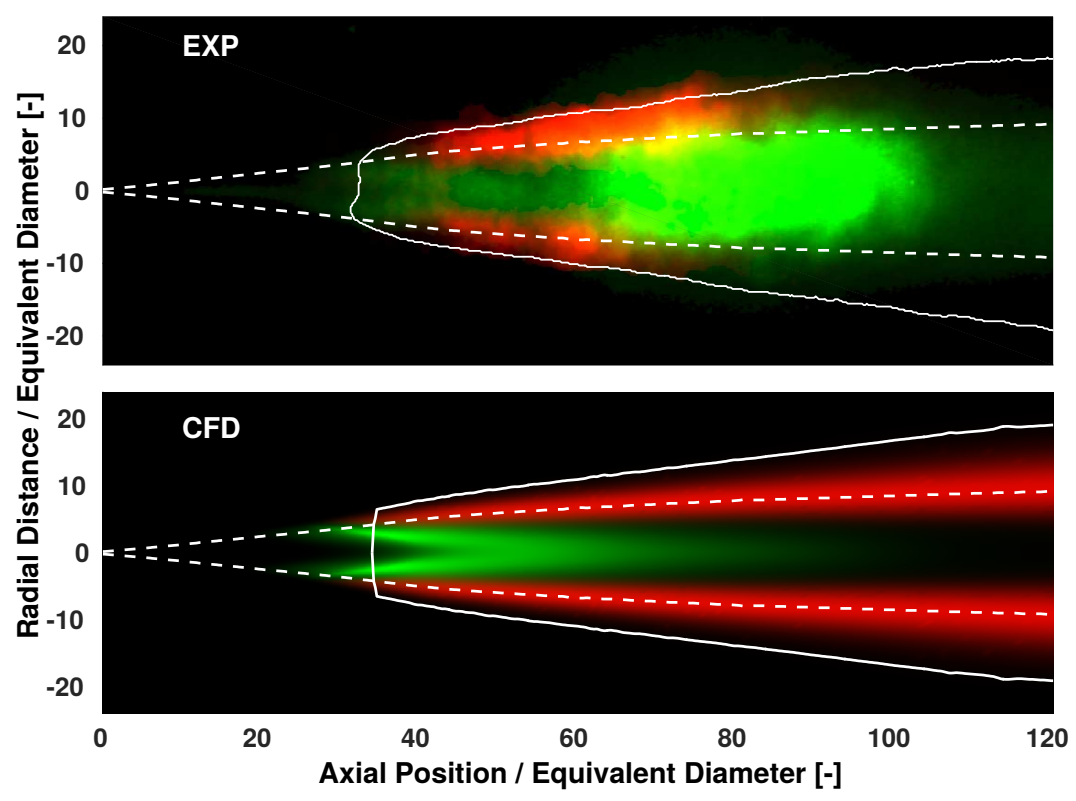

Figure 6: Comparison of predicted $\mathrm{CH}_{2} \mathrm{O}$ (green) and $\mathrm{OH}$ (red) with PLIF imaging at a quasi-steady state for SA condition. Color areas normalized by the maximum of each species respectively 


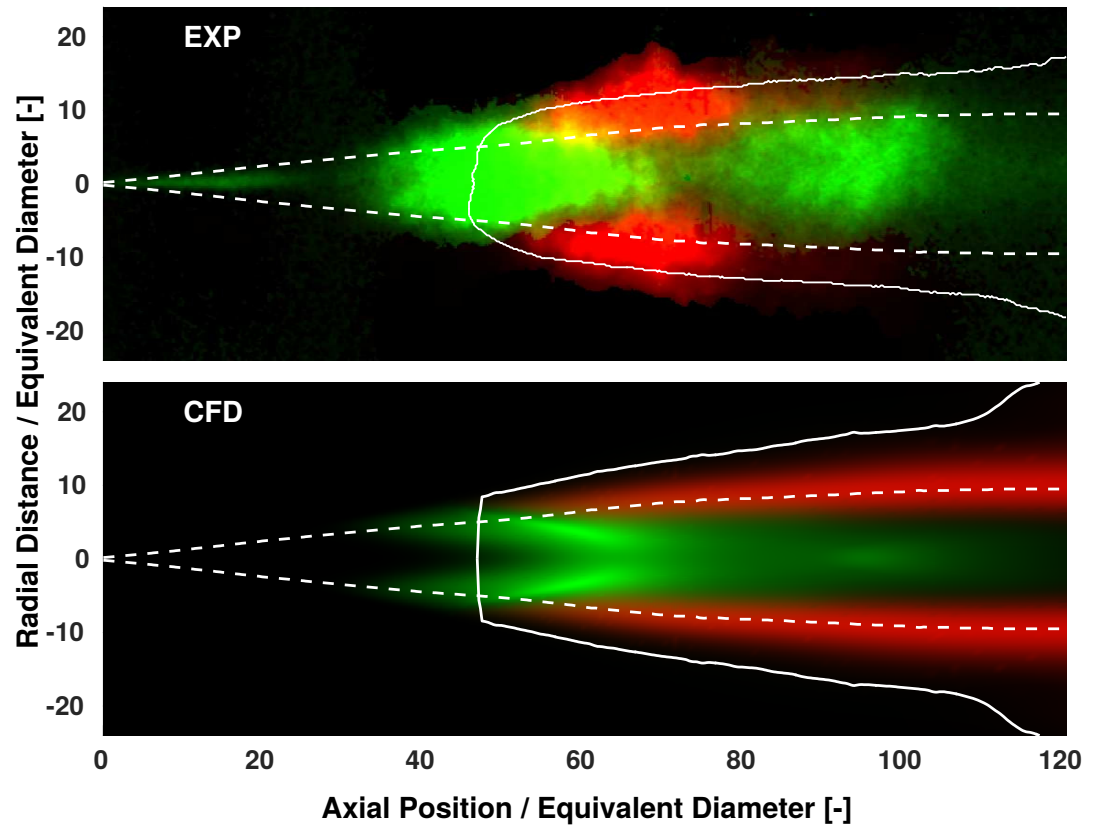

Figure 7: Comparison of predicted $\mathrm{CH}_{2} \mathrm{O}$ (green) and $\mathrm{OH}$ (red) with PLIF imaging at a quasi-steady state for $\mathrm{T} 2$ condition. Color areas normalized by the maximum of each species respectively

model around $25 d_{e q}$ downstream the nozzle exit. This specie is considered an indicator of low-intermediate temperature chemical reactions (cool-flame) and because of that, it appears slightly upstream of the first $\mathrm{OH}$ location. In the case of experiments, some signal can be observed upstream CFD, which is mainly due to light reflections on the liquid length [16]. Modelled formaldehyde disappears from $60 d_{e q}$ downstream, due to the transition to the high temperature chemistry within the flame. However, experiments show a strong measured signal, which as discussed in [16] is most likely due to the presence of PAHs. Regarding modelled $\mathrm{OH}$ distribution, location is consistently predicted close to the stoichiometric location, but radial spreading is narrower in comparison with the experiment. It must be noted that discrepancies in the axial extent downstream of $100 d_{e q}$ are due to the lasersheet dimensions limit in the measurement.

Results for T2 and EX conditions are shown in Fig. 7 and Fig. 8. Consistently with LoL measurements, the flame base location is properly predicted in both cases, with EX flame stabilizing downstream of T2 case. Formalde- 


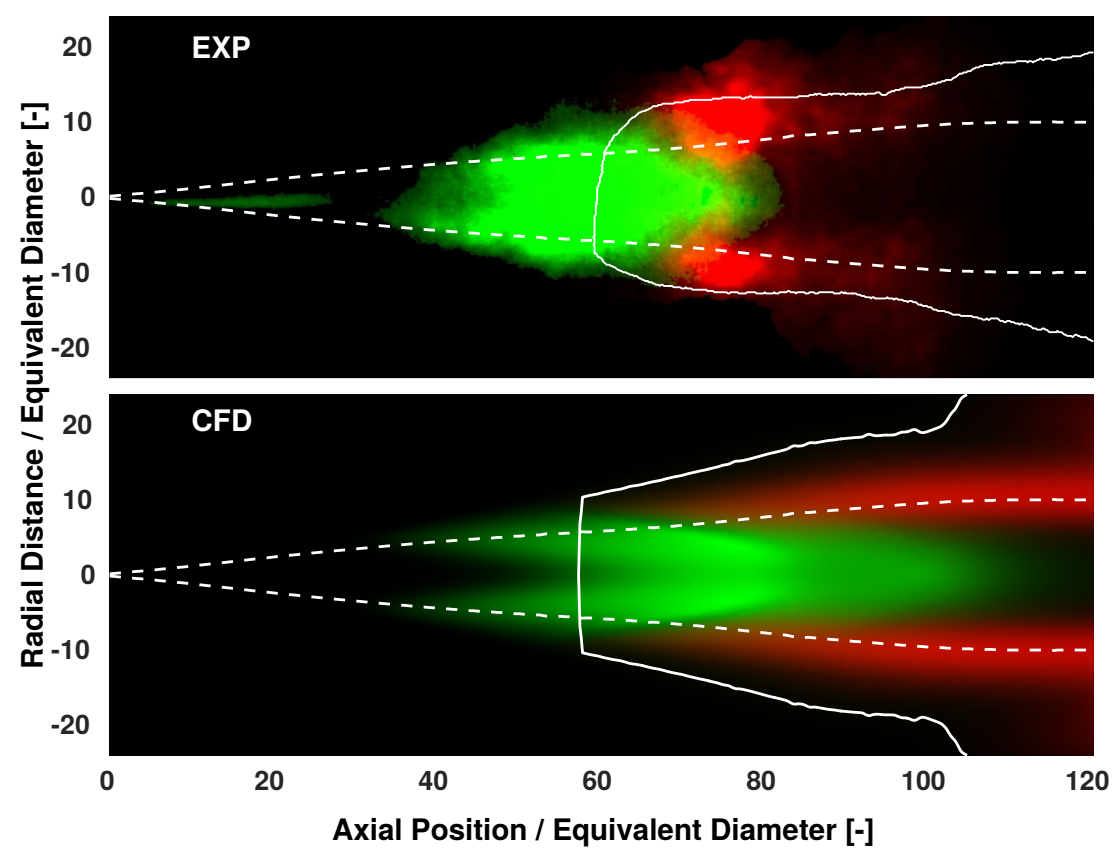

Figure 8: Comparison of predicted $\mathrm{CH}_{2} \mathrm{O}$ (green) and $\mathrm{OH}$ (red) with PLIF imaging at a quasi-steady state for EX condition. Color areas normalized by the maximum of each species respectively

hyde is seen to appear upstream of the LoL location in both cases, with a peak located at the a similar axial coordinate where $\mathrm{OH}$ appears, reflecting the transition between low and high temperature stages within the flame. Further downstream formaldehyde disappears pretty fast in modeling results, while a second peak can be observed for the experimental T2 results at around $90-100 d_{e q}$, which is also discussed to be due to PAHs interference [16]. For EX condition, formaldehyde takes longer to disappear compared to experiments. This fact, together with the observed overprediction of ID by the modeling, may confirm that with the present chemical mechanism the transition from the low to the high temperature stages is slower than in experiments. Finally, $\mathrm{OH}$ appears downstream of formaldehyde in both modeling and experiments, and is preferentially located around the stoichiometric location. Although experimental results are limited in axial extent, comparison hints at a narrower radial distribution in CFD compared to experiments, which has also been observed for SA condition. In any case, it 
is expected that moving to a LES turbulence modeling approach, where the large eddies are solved containing most of the turbulent energy and being responsible for most of the momentum transfer and turbulent mixing, both discussed disagreements (slow flame evolution from low to high temperature and the slightly narrower spray radial expansion) should be overcome in great deal.

\subsection{Analysis of local flow}

Fig. 9 shows the transient evolution of the flow for reacting SA condition in terms of profiles on-axis velocity and the spray velocity radius ( $5 \%$ of the on-axis velocity value). A reference profile under inert conditions has also been included. Note that normalized velocity and spatial coordinates are used, with the respective scaling in terms of nozzle velocity and equivalent diameter $d_{e q}=d_{0} \sqrt{\rho_{f} / \rho_{a}}$. The initial part of the velocity profile overlaps with the inert one until around $30 d_{e q}$, position from which the reacting cases evolve with higher values. Taking into account that the computational ignition delay is in the vicinity of $500 \mu \mathrm{s}$, it is possible to observe an inert to reacting transition between $500 \mu \mathrm{s}$ and $700 \mu \mathrm{s}$. Then, a progressive flow acceleration is experimented till $1000 \mu \mathrm{s}$, time from which flow develops in a quasi-steady manner, i.e. the velocity remains steady along the main part of the spray while only the tip continues extending. In comparison with GarciaOliver et al. results [16], model shows a sharper transition period which is in accordance with the overprediction observed at the ignition delay predictions. Compared to the inert profile, the flow acceleration under reacting conditions evidences velocities up to a $60 \%$ higher and with a longer extent of the spray tip, which corresponds with a faster penetration in agreement with experimental observations of transient tip penetration under reacting conditions [16]. Considering momentum conservation, as ambient density drops due to heat release, the velocity value increases. Similar conclusions can be drawn for both T2 and EX conditions (not shown).

Aside from the increase in local velocity, heat release induces a radial expansion of the spray $[16,42]$, which can be captured by the CFD model as shown in Fig. 9 on the right. The same transition period as for the onaxis velocity can be observed here as in the axial profiles. The radius of the first two instants are really close to the inert one, while at $700 \mu \mathrm{s}$ the radial dilation becomes noticeable. Once the reacting evolution has started, the spray mainly grows at the tip, while keeping the maximum width almost constant in the remaining quasi-steady part, in agreement with experimental 

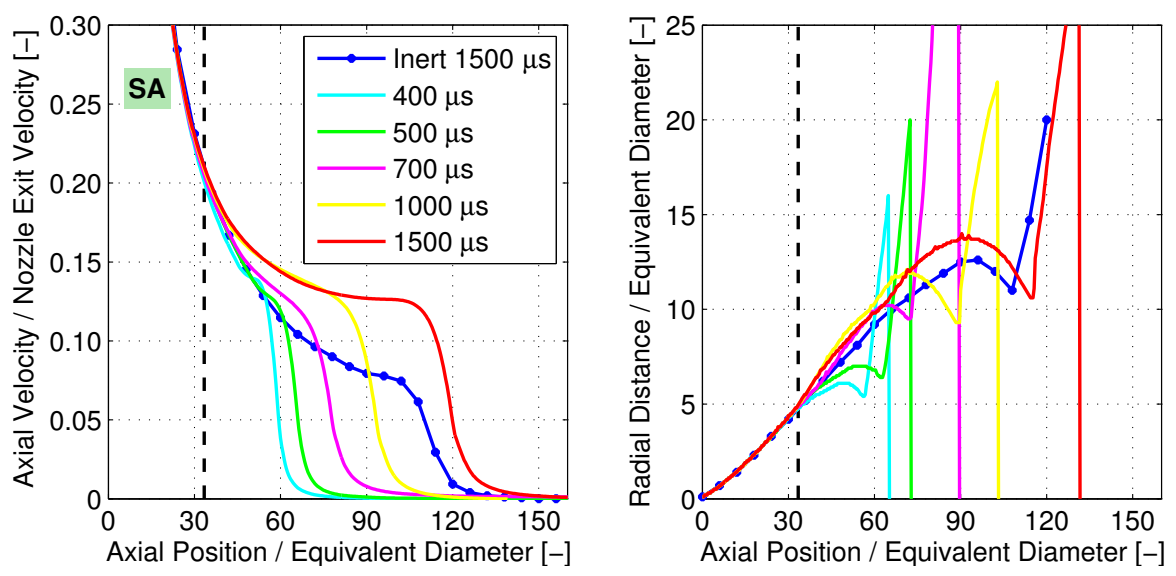

Figure 9: Time development of computed on-axis velocity [left] and spray radius [right] for reacting conditions, together with lift-off length position derived from $\mathrm{OH}^{*}$ visualization (dashed black lines). SA condition

observations [16]. Additionally, it is important to remark that the increase in the radius starts at the axial position that corresponds with the OH-derived lift-off length.

To assess model performance compared to experiments, results at steady state conditions is made in Fig. 10, both in terms of axial velocity on the centerline and spray contour. Together with the reacting profile, a reference profile under inert conditions has also been included. Predicted velocity values on the axis show good agreement with measurements, for both the inert and the reacting ambient conditions. This occurs both in magnitude and spatial distribution, with a clear transition at the LoL. The agreement is not as good for the EX reacting condition, probably as a consequence of the delayed ignition process in the case of the CFD simulation in comparison with the measurements.

On the other hand, in Fig. 10 the flow radius can also be compared. Due to the fact that for the nominal condition (SA) the end of injection occurs at $1.5 \mathrm{~ms}$, and the reacting spray is not fully developed, the unsteady head of the spray affects the regions upstream. This makes it difficult to quantify the combustion-induced radial dilation, which is due to the heat release process, although it can be still observed starting around the zone at which the flame LoL is located. For T2 and EX cases this combustion-induced increase in radius is more clearly distinguishable. Modeling prediction of the radial dilation occurring at the lift-off length are in agreement with measurements, 

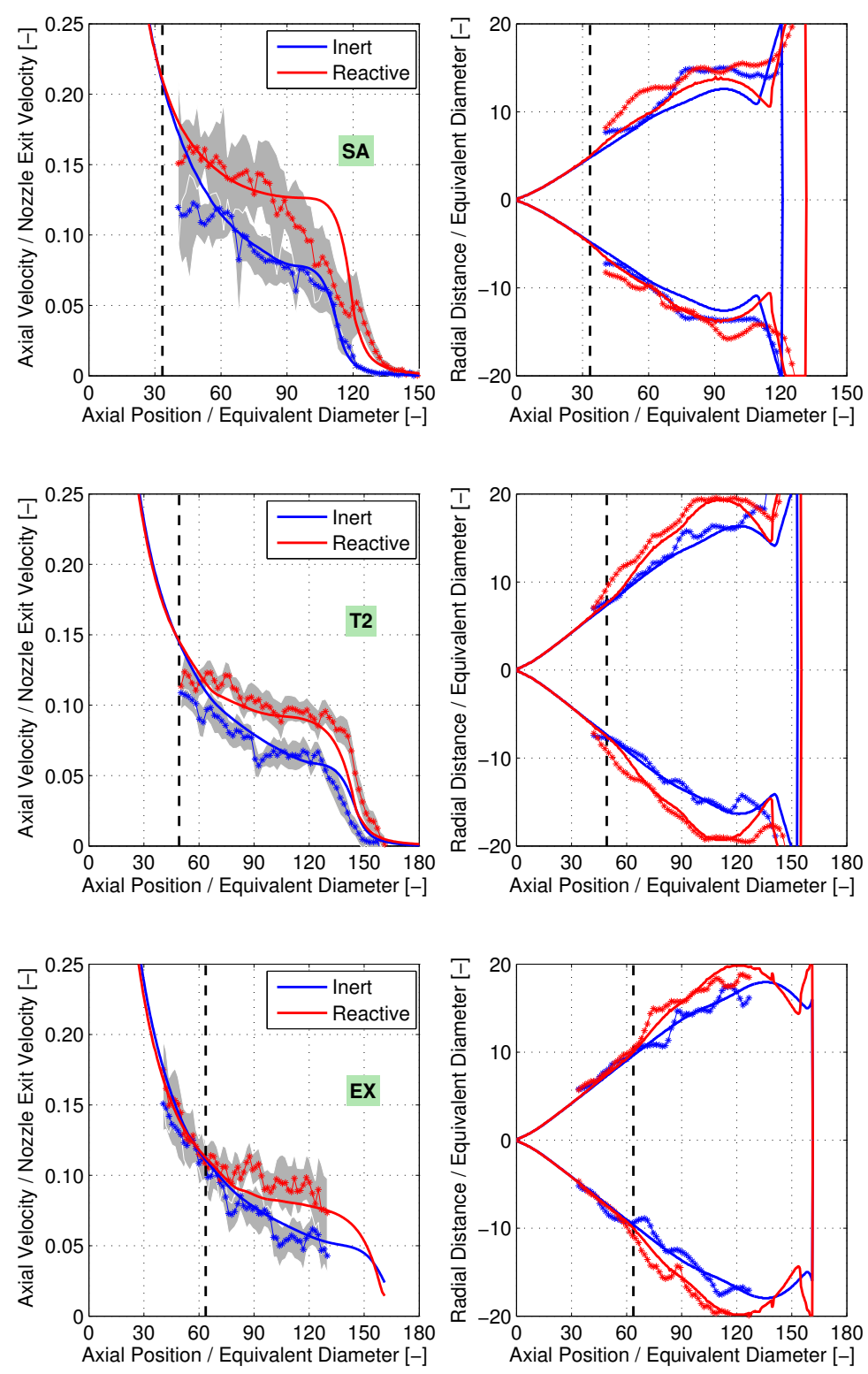

Figure 10: Computed and measured on-axis velocity [left] and spray contours [right] for inert (blue) and reacting (red) conditions, together with lift-off length position derived from $\mathrm{OH}^{*}$ visualization (dashed black lines). SA condition (top), T2 (middle) and EX (bottom) 
both in magnitude and starting point.

Finally, for the nominal case, an analysis of the radial profiles of the axial velocity component is shown in Fig. 11. Four axial locations $\left(40 d_{e q}\right.$, $60 d_{e q}, 80 d_{e q}$ and $100 d_{e q}$ ) are presented. In general, the shape is adequately captured by the CFD model, although with a slightly narrower radial distribution. Largest discrepancies can be found at $40 d_{e q}$ for both, inert and reacting conditions, accounting for width errors of around $16 \%$ and $25 \%$ respectively. This effect, together with the already mentioned narrower $\mathrm{OH}$ profiles, indicates that the radial dispersion as from the CFD model underestimates the actual radial dispersion, most probably due to limitations in the turbulence model. Similar conclusions can be drawn for the other two conditions.

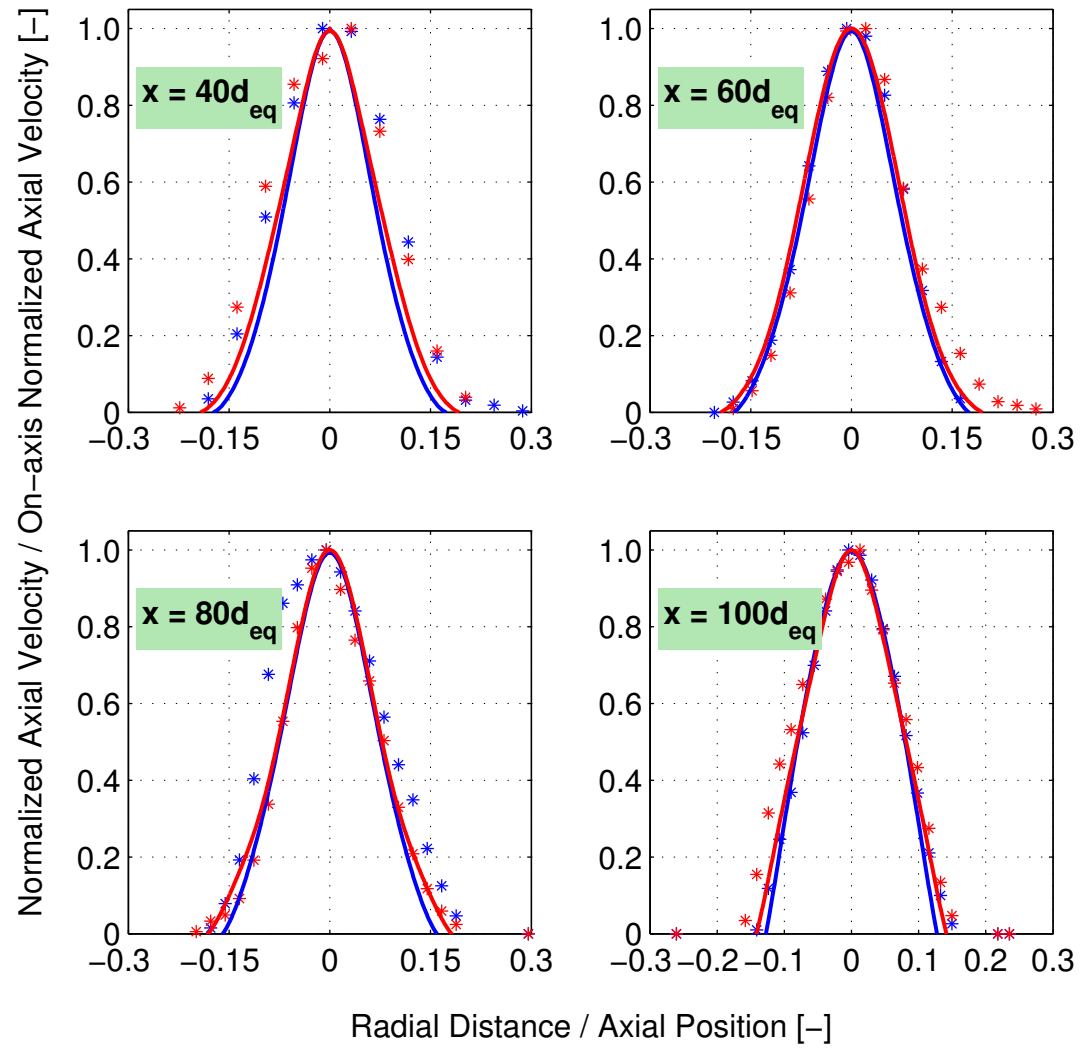

Figure 11: Computed (lines) and measured (points) velocity radial profiles normalized at $40 d_{e q}, 60 d_{e q}, 80 d_{e q}$ and $100 d_{e q}$ for inert (blue elements) and reacting (red elements) conditions. SA condition, $P_{i n j}=150 \mathrm{MPa}, \rho_{a m b}=22.8 \mathrm{~kg} / \mathrm{m}^{3}$ and $T_{a m b}=900 \mathrm{~K}$ 


\subsection{Analysis of ambient air entrainment}

In turbulent jets, 'entrainment' is the process by which ambient fluid is driven into the jet. This process is a fundamental factor in the evolution of direct injection Diesel sprays, as it controls the fuel-air mixing rate, with direct implications on the evaporation $[54,55]$ and combustion processes. This parameter has been investigated especially for atmospheric gas jets, but quantification under Diesel engine conditions is not so common, either in terms of experiments or with modeling tools. Recent measurements shown by [13] and [16] have provided evaluation of entrainment rate under Diesel engine conditions by means of PIV for both inert and reacting sprays, which will be analyzed here by means of CFD predictions. For that purpose, the entrainment coefficient is defined as

$$
C_{e}(x)=\frac{d \dot{m}}{d x} \frac{d_{e q}}{\dot{m}_{0}}
$$

where $\dot{m}$ is the mass flux across a full radial cross-section of the spray, $\dot{m}_{0}$ the mass flux at the orifice, $x$ the downstream axial distance and $d_{e q}$ the equivalent diameter. Then, entrainment rate is computed as a function of axial distance, considering that the spray radial limit is located at the radial position where the velocity is equal to $1 \%$ of the on-axis velocity.

$$
\dot{m}(x)=\int \rho u d A=\int_{0}^{R} \rho u 2 \pi r d r
$$

Computed local entrainment rate results are shown in Fig. 12 for SA condition. Values have been averaged in the $2800-4400 \mu$ s interval in order to ensure quasi-steady state predictions in a wide extension of the spray. No comparison with measured derived local values is made as a consequence of the short experimental injection duration for this operation point, which means that the spray is under unsteady conditions within the observation window. Starting with the inert profile, one can observe a first transient region located near the nozzle (below $20 d_{e q}$ ), where $C_{e}(x)$ has a lower value in agreement to results in $[18,19]$ because of the transition between the nozzle and the fully developed turbulent spray. After that, a relatively flat evolution can be seen with a value quite near to the reference one of 0.28 derived in [13]. This is slightly lower than the classical value of 0.32 for free gas jets from Ricou \& Spalding [51]. Nevertheless, as proposed in [13], $C_{e}(x)$ for Diesel sprays can be different depending on the nozzle characteristics, which 


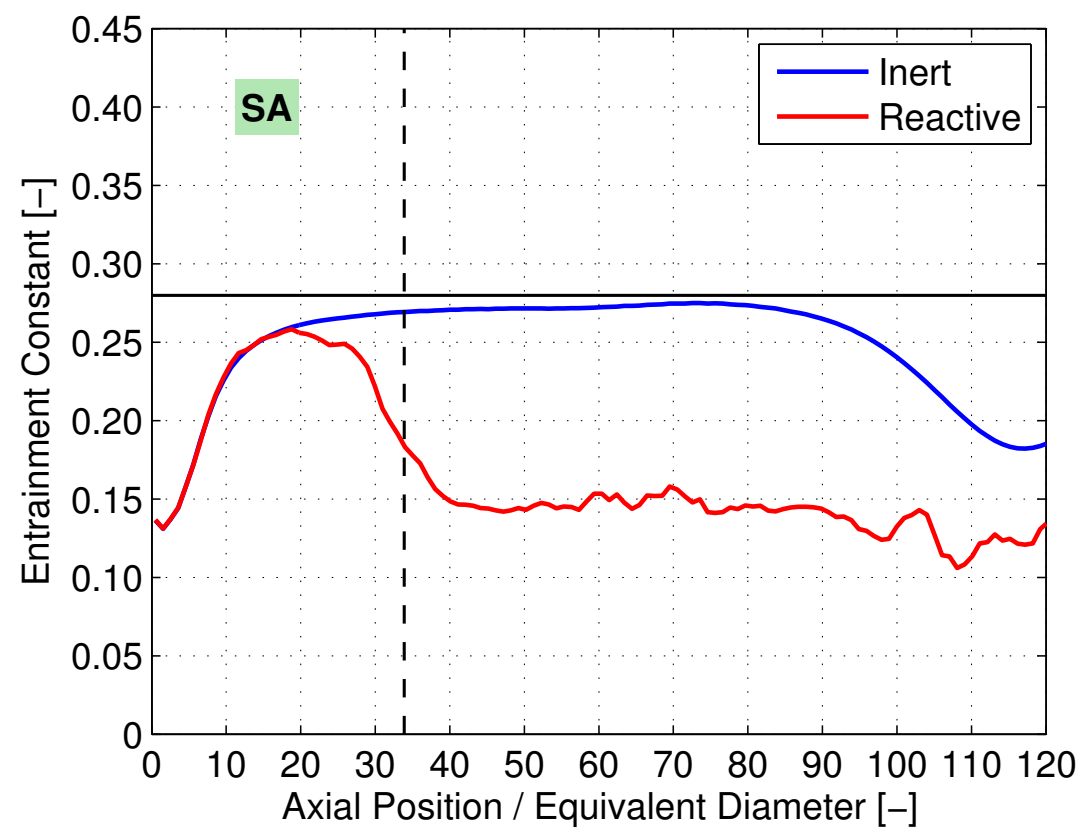

Figure 12: Computed entrainment constant for inert (blue elements) and reacting (red elements) conditions averaged in the $2800-4400 \mu$ s interval after SOI. Vertical dashed line indicates the LoL location. Horizontal line indicates the 0.28 reference value derived from [13]. SA condition, $P_{i n j}=150 \mathrm{MPa}, \rho_{a m b}=22.8 \mathrm{~kg} / \mathrm{m}^{3}$ and $T_{a m b}=900 \mathrm{~K}$

may result in a particular spray angle, and thus a related air entrainment constant. Lower values downstream $95 d_{e q}$ are a consequence of the effect of the transient tip of the spray. Moving to reacting conditions, the entrainment rate profile at the first region (below $20 d_{e q}$ ) is exactly the same as the inert one. Then, its evolution presents a decay (around a 45\%) which drives the entrainment rate towards a value of around 0.15. Apart from the quantitative evaluation of the entrainment decrease due to heat release, which is similar to that occurring for gas jets, the interesting point is that the entrainment reduction starts slightly upstream of the calculated lift-off length location. Compared to that, heat release effects on the local velocity on the spray axis were only found downstream of the lift-off length (e.g. Fig. 9).

The previous behaviour of the reacting flow can be explained as a consequence of a density drop and a simultaneous velocity increment before the lift-off length axial position. In Fig. 13, a comparison between radial profiles of density and axial velocity is made for both SA conditions (inert and re- 

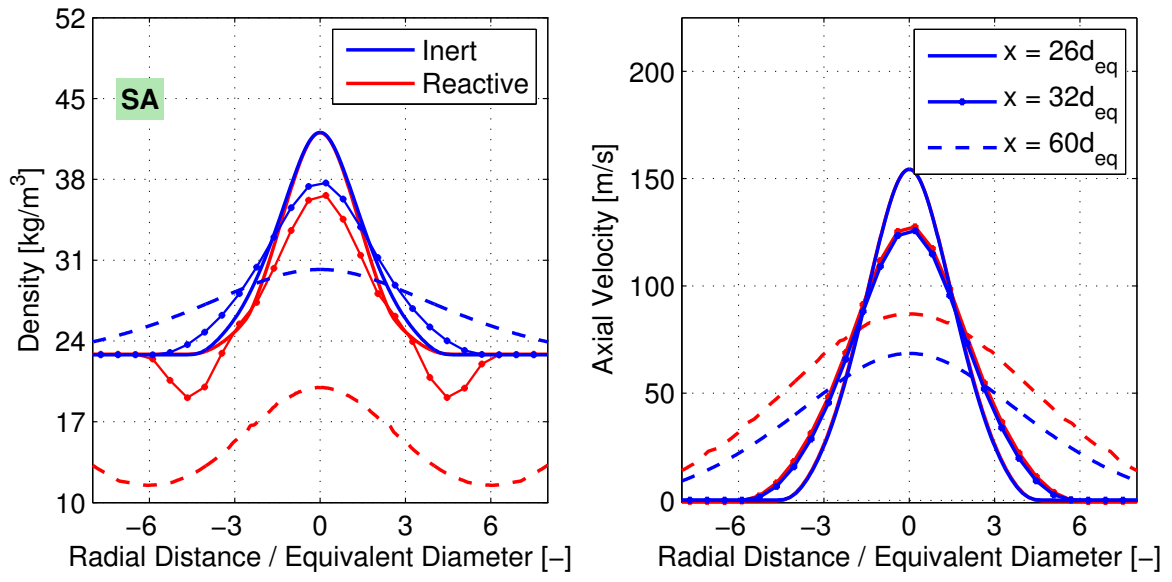

Figure 13: Computed radial profiles of density [left] and velocity [right] at $26 d_{e q}$ (solid line), $32 d_{e q}$ (dotted line) and $60 d_{e q}$ (dashed line) for inert (blue elements) and reacting (red elements) conditions averaged in the $2800-4400 \mu$ s interval after SOI. SA condition, $P_{i n j}=150 \mathrm{MPa}, \rho_{a m b}=22.8 \mathrm{~kg} / \mathrm{m}^{3}$ and $T_{a m b}=900 \mathrm{~K}$

acting). Two sections at $26 d_{e q}$ (solid line) and $32 d_{e q}$, i.e. slightly upstream and just at the lift-off length are shown, and one more further downstream $\left(60 d_{e q}\right)$ is also included to have information of a section at which the reacting flow is completely developed. Differences between inert and reacting contours are noticeable in case of density profiles. While at $26 d_{e q}$ a very slightly reduction of density value is observed at the radial limit of the spray in the reacting case, at $32 d_{e q}$ the density drop is more apparent throughout the spray cross-section. Finally, at $60 d_{e q}$ density is clearly below the inert ambient density value due to the high temperature induced by the combustion process. On the other hand, as local density drops the velocity value should increase. However, in this case this acceleration is only noticeable at $60 d_{e q}$, with no evidence found upstream.

The previous result suggests that the entrainment drop occurring in the vicinity of the LoL is to a large extent a consequence of the density drop with the combustion-induce increase in temperature, rather than because of a change in local velocity, which mainly occurs downstream the LoL, when the flame structure is fully established. This can be further confirmed when considering the different species evolving within the spray, as well as the temperature. Fig. 14 shows the radial distribution of $\mathrm{CH}_{2} \mathrm{O}$ and $\mathrm{OH}$ (with a 10x scaling factor), as indicators of low- and high-temperature chemistry, respectively, and $T$ (temperature), for both inert and reacting ambient, to 
evaluate the local evolution of the combustion process. Similarly to the analysis of density and velocity, axial locations at $20 d_{e q}, 26 d_{e q}, 32 d_{e q}$ and $60 d_{e q}$ have been selected.

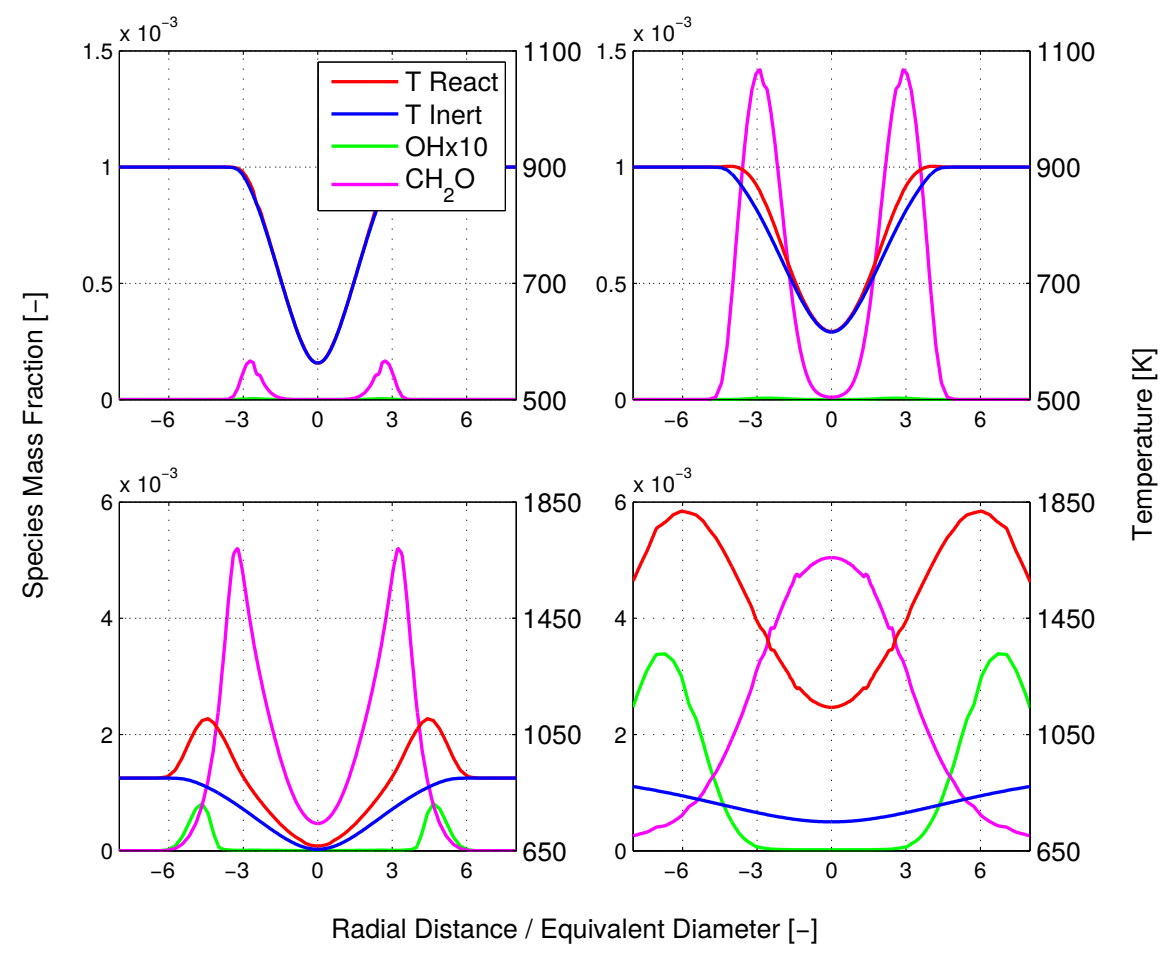

Figure 14: Computed radial profiles of $T$ under reacting conditions, $T$ under inert conditions, $\mathrm{OH} x 10$ and $\mathrm{CH}_{2} \mathrm{O}$ at $20 d_{e q}$ (top left), $26 d_{e q}$ (top right), $32 d_{e q}$ (bottom left) and $60 d_{e q}$ (bottom right) averaged in the 2800-4400 $\mu$ s interval after SOI. SA condition, $P_{i n j}=150 \mathrm{MPa}, \rho_{a m b}=22.8 \mathrm{~kg} / \mathrm{m}^{3}$ and $T_{a m b}=900 \mathrm{~K}$

At the first axial location, the reaction has hardly started at all, with both temperature profiles almost identical and a maximum around $900 \mathrm{~K}$ (ambient temperature), together with the presence of a marginal amount of formaldehyde $\left(\mathrm{CH}_{2} \mathrm{O}\right)$. Further downstream, at $26 d_{e q}$ low temperature reaction process is starting, reacting temperature profile presents an increment at the radial limit, where overall temperature evolution is clearly higher than the inert one, although the peak value is just slightly higher (around $2 \mathrm{~K}$ ) than the ambient temperature. This fact produces a substantial amount of $\mathrm{CH}_{2} \mathrm{O}$ while $\mathrm{OH}$ mass fraction is still non-existent. At $32 d_{e q}$ reaction has progressed at the radial limits of the spray, while in the spray core tempera- 
ture profile suggests that it is just starting. Thus, some $O H$ mass fraction is formed, driving the spray into the high temperature stage. Also, formaldehyde maximum peak is almost four times greater than in the previous axial location, but it is still located at the radial spray limit in agreement with the spatial region at which the density drops abruptly. Finally, at $60 d_{e q}$ the combustion process has changed from the LoL region (partially premixed combustion) to the pure diffusion flame zone. Here, it is possible to observe that the reaction has been fully established within the spray core, with high temperature values coinciding with locations where $\mathrm{OH}$ peaks. On the other hand, formaldehyde peaks at the spray centerline, and radially drops showing again the transition between low and high temperature stages.
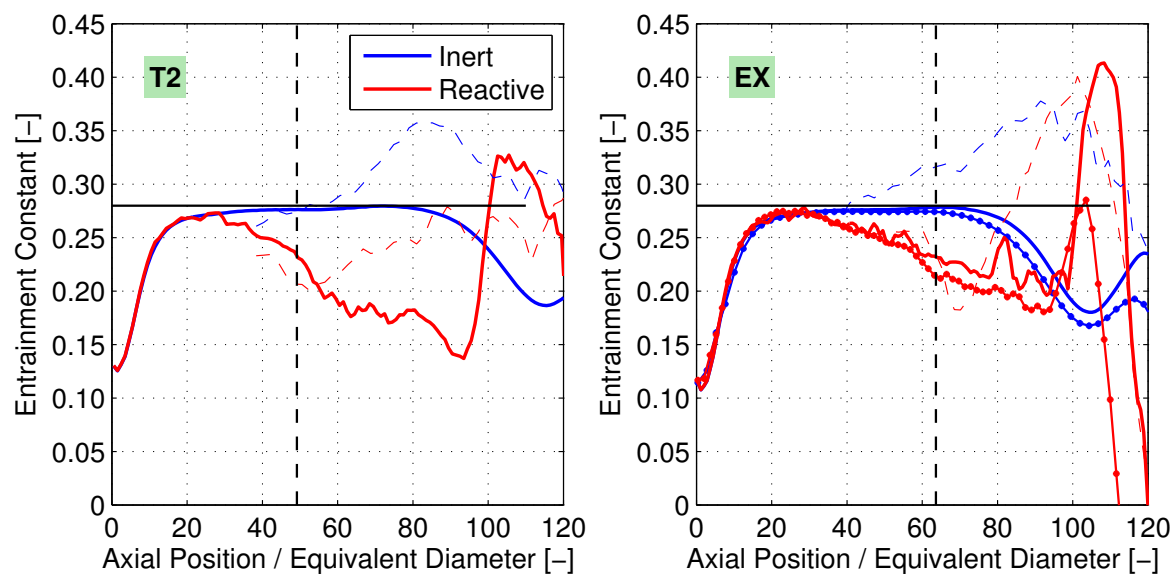

Figure 15: Computed (solid line), computed closed domain (dotted line) and measured (dashed line) entrainment constant for inert and reacting conditions averaged in the 2800$4400 \mu \mathrm{s}$ interval after SOI. Vertical dashed line indicates the LoL location. Horizontal line indicates the 0.28 reference value derived from [13]. T2 (left) and EX (right) conditions

Considering the other two operating conditions evaluated, the same overall behaviour observed for the nominal condition is perceived in these cases. The inert entrainment rates are shown to be around the reference value of 0.28 , while the reacting profile drops below this value with the entrainment reduction located again just in the vicinity of the LoL axial location. While measured values for SA condition only happen downstream of the LoL, for both T2 and EX conditions experiments also extend towards the upstream location, and therefore the transition in the flow from inert to reacting conditions can be validated. In contrast with the evolution observed for SA, which is relatively flat after the drop in entrainment at the LoL, for these 
two ambient variations the entrainment rate keeps decreasing over the measured range. In this case the final drop in entrainment is around $25 \%$ of the inert value, similarly to experiments [16]. In addition, simulations with a closed domain have been included for EX condition. It must be noted that differences in ID or LoL between open and closed domains are negligible, with a maximum $2 \%$. Entrainment constant profile with closed domain is quite similar to the open one, with just a small offset (approximately 0.02 drop) towards lower values for the closed case. This indicates that flow confinement produces a small reduction in entrainment, which is quantitatively small compared to, for example, heat release effect.
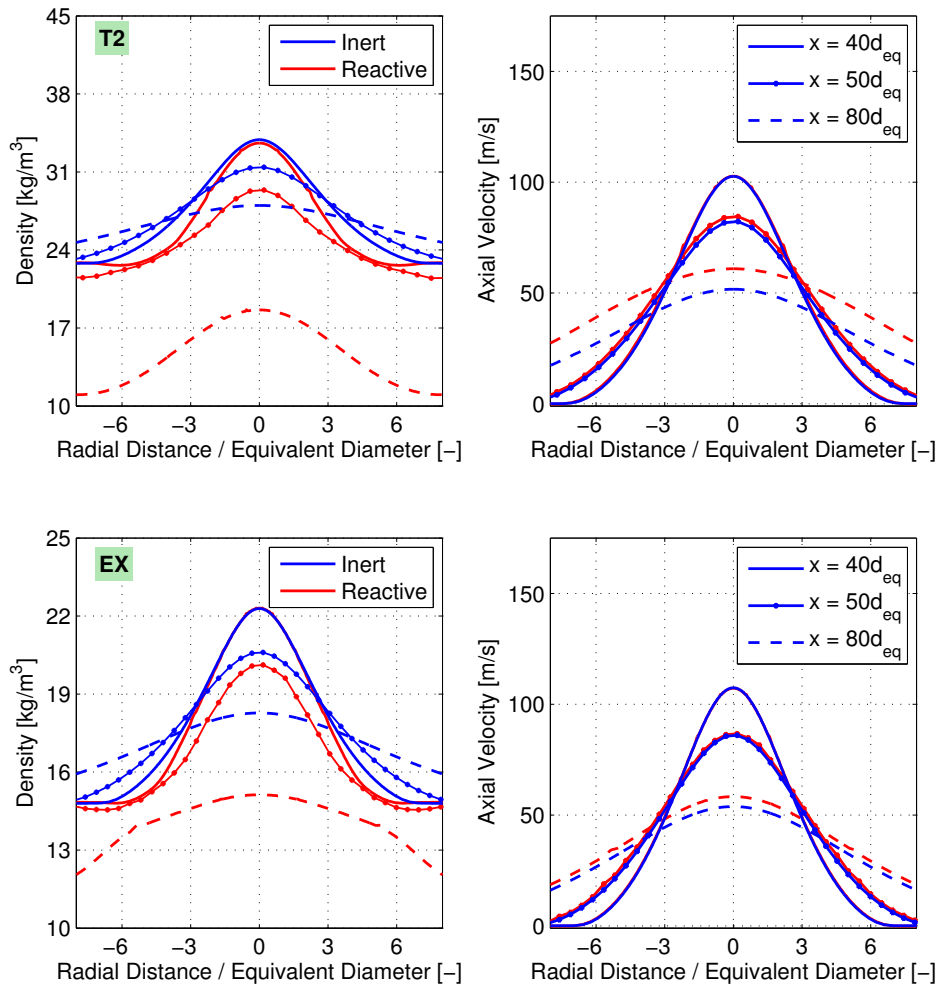

Figure 16: Computed radial profiles of density [left] and velocity [right] at $40 d_{e q}$ (solid line), $50 d_{e q}$ (dotted line) and $80 d_{e q}$ (dashed line) for inert (blue elements) and reacting (red elements) conditions averaged in the $2800-4400 \mu$ s interval after SOI. T2 condition (top) and EX (bottom)

Fig. 16 shows radial profiles of density and velocity at $40 d_{e q}, 50 d_{e q}$ and 
$\left.80 d_{e q}\right)$ from the nozzle for both T2 and EX operating conditions. Overall results are similar to the $\mathrm{SA}$ condition. In terms of density, the reduction is noticeable from the first axial location, being sharper in the radial limit of the spray with subsequent evolution following the pattern observed for SA condition. On the other hand, close to the LoL location velocity profiles are quite similar for both inert and reacting conditions, and differences are only noticeable once the flame structure is fully established $\left(80 d_{e q}\right)$, where the acceleration of the flow can be clearly seen. This confirms that initial low temperature reactions slightly reduce entrainment upstream of the liftoff length due to density drop, with no effect on velocity. It is downstream of the lift-off length when the flow responds in terms of velocity, but final entrainment rate is below the inert case due to the strong increase in temperature.

Finally, further investigations on the previous effects can be made by means of streamlines shown in Fig. 17, which have been generated starting at $r=32 d_{e q}$ with points uniformly spaced in the axial coordinate. The analysis is made for the EX operating condition, showing streamlines for both open and closed domains, and both under inert and reacting conditions. Starting with the open geometry case, inert simulation shows an entrainment pattern perpendicular to the spray axis when the flow is outside of the spray radial limit, which turns and becomes almost axial within the spray contour. This pattern is characteristic of a free jet injected into an infinitum atmosphere. For the reacting case, the entrained flow is still perpendicular to the axis until the LoL axial location, where streamlines start to change in angle compared to the perpendicular direction. Furthermore, there is a noticeable separation between adjacent streamlines downstream the LoL location, which hints at a reduction in local mass flow, i.e. entrainment. Inside the spray, streamlines also show a change in slope at the LoL from the almost horizontal position that can be observed in the inert case. All previous effects confirm the previously discussed effects of increasing temperature within the flow, and are in agreement with experimental results in [16].

One of the open questions that turned up from the experiments is whether the change in streamline direction away from the spray limits is only due to combustion, or it could also be due to recirculation from the spray tip due to the unsteady head vortex. The latter effect is less important in the open domain simulations, where the inert streamlines have shown that the spray entrainment characteristics stem from the non-perturbed flow. However, when considering the closed domain, some departure from the perpendicular di- 

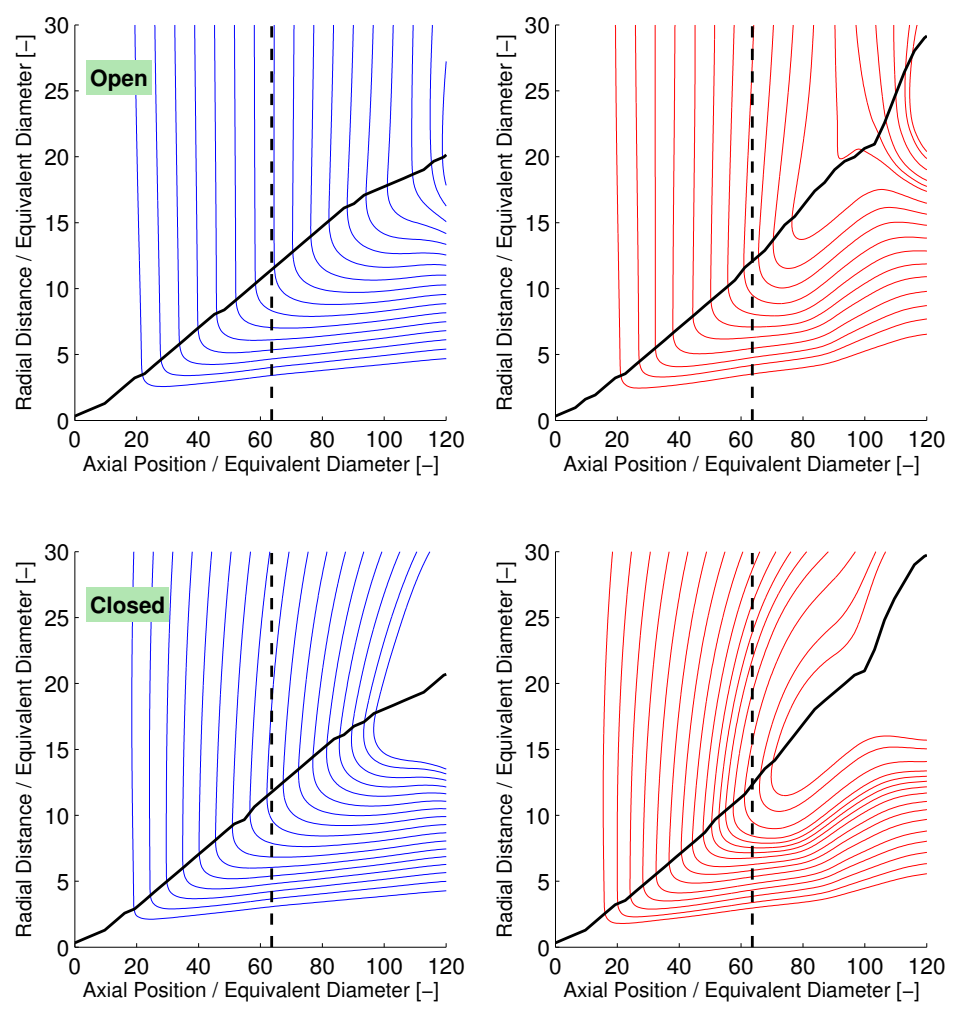

Figure 17: Computed streamlines for inert (left) and reacting (right) conditions and LoL location (dashed black line). EX condition, $P_{i n j}=150 \mathrm{MPa}, \rho_{a m b}=14.8 \mathrm{~kg} / \mathrm{m}^{3}$ and $T_{a m b}=780 \mathrm{~K}$. Open domain (top) and closed domain (bottom)

rection can be observed for the streamlines outside of the spray even in the inert case, as a consequence of flow confinement within the actual volume of the spray vessel. Fig. 17 shows that the effect is more evident in the reacting case, where the curvature of the streamlines already happens upstream of the LoL location. However, when integrated into the entrainment coefficient, the previous flow effect do not change much when moving from closed to open domains. Therefore, even though some details of the local flow seem to change around the LoL location, global combustion and flow indicators are not largely affected by flow confinement. 


\section{Summary and Conclusions}

A new solver for simulation of reacting Diesel sprays has been constructed by coupling the $\Sigma$-Y Eulerian atomization model [17] with an ADF combustion model [65] in the OpenFOAM CFD platform. Calculations have been validated against PIV measurements of both inert and reacting Spray A conditions of ECN, conducted at IFPEN constant-volume pre-burn vessel.

The model has produced accurate LoL predictions, with poorer ID agreement when going to low temperature cases, most probably due to the limitations in the chemical mechanism. In any case, comparison with experiments has shown a quite fair description of the internal structure of the reacting spray in terms of formaldehyde and $\mathrm{OH}$ distributions. Detailed flow analysis has shown that the CFD model predicts the increase in local velocity and radial dilation as a consequence of combustion-induced density drop. This flow acceleration is well captured in comparison with experimental measurements, showing a maximum increase of around $60 \%$ and starting to be experimented from the LoL axial position downstream. Both flow analysis and flame structure hints, however, at a slightly reduced radial dispersion of the spray compared to experiments.

Moreover, analysis of entrainment rate under reacting conditions shows a first reduction upstream of the LoL as a consequence of combustion-induced temperature increase, which continues progressing till the flame base stabilization region where the reduction reaches a value comprised between $25 \%$ to $45 \%$ for the investigated conditions. This reduction upstream of the LoL is not due to flow confinement, but rather to the initial density drop due to the low temperature reaction phase. Only downstream LoL starts the flow to reorganize, i.e. to increase velocity, in response to the temperature increase.

In summary, the new solver provides a quite fair performance, being able to predict and explain the main changes in the flow pattern experimented under reacting conditions compared to inert ones.

\section{Acknowledgement}

Authors acknowledge that this work was possible thanks to the Programa de Ayudas de Investigación y Desarrollo (PAID-2013 3198) of the Universitat Politècnica de València. Also this study was partially funded by the Spanish Ministry of Economy and Competitiveness in the frame of the COMEFF(TRA2014-59483-R) project. Authors thank Gilles Bruneaux from IFPEN for the interesting suggestions and discussions. 


\section{References}

[1] Bazdidi-Tehrani, F. and Zeinivand, H., Presumed PDF modeling of reactive two-phase flow in a three dimensional jet-stabilized model combustor, Energy Conversion and Management, vol. 51, no. 1, pp. 225 - 234, 2010.

[2] Beau, P., Funk, M., Lebas, R., and Demoulin, F., Applying quasi-multiphase model to simulate atomization processes in diesel engines: Modeling of the slip velocity, SAE Technical Paper 2005-01-0220, 2005.

[3] Beheshti, N., Burluka, A., and Fairweather, M., Assessment of $\Sigma-Y$ liq model predictions for air-assisted atomisation, Theoretical and Computational Fluid Dynamics, vol. 21, no. 5, pp. 381-397, 2007.

[4] Blokkeel, G., Barbeau, B., and Borghi, R., A 3D Eulerian model to improve the primary breakup of atomizing jet, SAE Technical Paper 2003-01-005, 2003 .

[5] Dahms, R. N., Manin, J., Pickett, L. M., and Oefelein, J. C., Understanding high-pressure gas-liquid interface phenomena in diesel engines, Proceedings of the Combustion Institute, vol. 34, no. 1, pp. 1667 - 1675, 2013.

[6] Demoulin, F., Beau, P., Blokkeel, G., Mura, A., and Borghi, R., A new model for turbulent flows with large density fluctuations: application to liquid atomization, Atomization and Sprays, vol. 17, pp. 315-345, 2007.

[7] Demoulin, F.-X., Reveillon, J., Duret, B., Bouali, Z., Desjonqueres, P., and Menard, T., Toward using direct numerical simulation to improve primary break-up modeling, Atomization and Sprays, vol. 23, no. 11, pp. 957-980, 2013.

[8] Desantes, J., García-Oliver, J., Novella, R., and Pérez-Sánchez, E., Application of an unsteady flamelet model in a RANS framework for spray A simulation, Applied Thermal Engineering, vol. 117, pp. 50 - 64, 2017.

[9] Desantes, J. M., García-Oliver, J. M., Pastor, J. M., and Pandal, A., A comparison of diesel sprays CFD modelling approaches: DDM vs $\Sigma-Y$ eulerian atomization model, Atomization and Sprays, vol. 26, no. 7, pp. 713-737, 2016.

[10] Desantes, J. M., García-Oliver, J. M., Pastor, J. M., Pandal, A., Baldwin, E., and Schmidt, D. P., Coupled / decoupled spray simulation comparison of the ECN spray a condition with the $\Sigma-Y$ eulerian atomization model, International Journal of Multiphase Flow, vol. 80, pp. 89 - 99, 2016. 
[11] Desportes, A., Zellat, M., Desoutter, G., Liang, Y., and Ravet, F., Application of the Eulerian-Lagrangian spray atomization (ELSA) model for the diesel injection simulation, THIESEL 2010 Conference on Thermo- and Fluid Dynamic Process in Diesel Engines, 2010.

[12] Dukowicz, J. K., A particle-fluid numerical model for liquid sprays, Journal of Computational Physics, vol. 35, no. 2, pp. 229 - 253, 1980.

[13] Eagle, W., Musculus, M., Malbec, L., and Bruneaux, G., Measuring transient entrainment rates of a condfined vaporizing diesel jet, ILASS Paper, 2014.

[14] ECN, Engine combustion network data archive, 2012.

URL http://www.sandia.gov/ecn/

[15] Frassoldati, A., D’Errico, G., Lucchini, T., Stagni, A., Cuoci, A., Faravelli, T., Onorati, A., and Ranzi, E., Reduced kinetic mechanisms of diesel fuel surrogate for engine $\{\mathrm{CFD}\}$ simulations, Combustion and Flame, vol. 162, no. 10, pp. $3991-4007,2015$.

[16] García-Oliver, J. M., Malbec, L.-M., Toda, H. B., and Bruneaux, G., A study on the interaction between local flow and flame structure for mixing-controlled diesel sprays, Combustion and Flame, vol. 179, pp. 157 - 171, 2017.

[17] García-Oliver, J. M., Pastor, J. M., Pandal, A., Trask, N., Baldwin, E., and Schmidt, D. P., Diesel spray CFD simulations based on the $\Sigma-Y$ eulerian atomization model, Atomization and Sprays, vol. 23, pp. 71-95, 2013.

[18] Han, D. and Mungal, M., Direct measurement of entrainment in reacting/nonreacting turbulent jets, Combustion and Flame, vol. 124, no. 3, pp. $370-386,2001$.

[19] Hill, B. J., Measurement of local entrainment rate in the initial region of axisymmetric turbulent air jets, Journal of Fluid Mechanics, vol. 51, no. 4, p. $773-779,1973$.

[20] Kastengren, A., Tilocco, F. Z., Powell, C. F., Manin, J., Pickett, L. M., Payri, R., and Bazyn, T., Engine combustion network (ECN):measurements of nozzle geometry and hydraulic behavior, Atomization and Sprays, vol. 22, pp. 1011-1052, 2012.

[21] Lacaze, G., Misdariis, A., Ruiz, A., and Oefelein, J. C., Analysis of highpressure diesel fuel injection processes using \{LES $\}$ with real-fluid thermodynamics and transport, Proceedings of the Combustion Institute, vol. 35, no. 2, pp. $1603-1611,2015$. 
[22] Lebas, R., Blokkeel, G., Beau, P., and Demoulin, F., Coupling vaporization model with the Eulerian-Lagrangian spray atomization (ELSA) model in diesel engine conditions, SAE Technical Paper 2005-01-0213, 2005.

[23] Lebas, R., Menard, T., Beau, P., Berlemont, A., and Demoulin, F., Numerical simulation of primary break-up and atomization: DNS and modeling study, International Journal of Multiphase Flow, vol. 35, pp. 247-260, 2009.

[24] Luo, Z., Som, S., Sarathy, S. M., Plomer, M., Pitz, W. J., Longman, D. E., and $\mathrm{Lu}, \mathrm{T}$., Development and validation of an n-dodecane skeletal mechanism for spray combustion applications, Combustion Theory and Modelling, vol. 18, no. 2, pp. 187-203, 2014.

[25] Malbec, L., Egúsquiza, J., Bruneaux, G., and Meijer, M., Characterization of a set of ecn spray a injectors: Nozzle to nozzle variations and effect on spray characteristics, SAE Int. J. Engines, vol. 6, no. 3, pp. 1642-1660, 2013.

[26] Ménard, T., Tanguy, S., and Berlemont, A., Coupling level set/vof/ghost fluid methods: Validation and application to $3 \mathrm{~d}$ simulation of the primary breakup of a liquid jet, International Journal of Multiphase Flow, vol. 33, no. 5, pp. $510-524,2007$.

[27] Michel, J.-B., Colin, O., Angelberger, C., and Veynante, D., Using the tabulated diffusion flamelet model adf-pcm to simulate a lifted methane-air jet flame, Combustion and Flame, vol. 156, no. 7, pp. 1318 - 1331, 2009.

[28] Michel, J.-B., Colin, O., and Veynante, D., Modeling ignition and chemical structure of partially premixed turbulent flames using tabulated chemistry, Combustion and Flame, vol. 152, no. 1-2, pp. 80 - 99, 2008.

[29] Michel, J.-B., Colin, O., and Veynante, D., Comparison of differing formulations of the pcm model by their application to the simulation of an autoigniting H2/air jet, Flow, Turbulence and Combustion, vol. 83, no. 1, pp. 33-60, 2009.

[30] Narayanaswamy, K., Pepiot, P., and Pitsch, H., A chemical mechanism for low to high temperature oxidation of n-dodecane as a component of transportation fuel surrogates, Combustion and Flame, vol. 161, no. 4, pp. 866 - 884, 2014.

[31] Naud, B., Novella, R., Pastor, J. M., and Winklinger, J. F., RANS modelling of a lifted $\mathrm{H} 2 / \mathrm{N} 2$ flame using an unsteady flamelet progress variable approach with presumed PDF, Combustion and Flame, vol. 162, no. 4, pp. 893 - 906, 2015 . 
[32] Navarro-Martinez, S., Large eddy simulation of spray atomization with a probability density function method, International Journal of Multiphase Flow, vol. 63, pp. $11-22,2014$.

[33] Ning, W., Reitz, R., Diwakar, R., and Lippert, A., An eulerian-lagrangian spray and atomization model with improved turbulence modeling, Atomization and Sprays, vol. 19, pp. 727,739, 2009.

[34] O'Brien, E. E., 1980. The probability density function PDF approach to reacting turbulent flows. Springer Berlin Heidelberg, Berlin, Heidelberg, pp. $185-218$.

[35] Oefelein, J., Dahms, R., and Lacaze, G., Detailed modeling and simulation of high-pressure fuel injection processes in diesel engines, SAE Int. J. Engines, vol. 5, no. 3, p. 10, 2012.

[36] Oefelein, J. C., Dahms, R. N., Lacaze, G., Manin, J. L., and Pickett, L. M., Effects of pressure on the fundamental physics of fuel injection in diesel engines, ICLASS Paper, 2012.

[37] Pandal, A., Implementation and Development of an Eulerian Spray Model for CFD simulations of diesel Sprays, PhD thesis, Departamento de Máquinas y Motores Térmicos, Universidad Politécnica de Valencia, España, 2016.

[38] Pandal, A., Pastor, J. M., García-Oliver, J. M., Baldwin, E., and Schmidt, D. P., A consistent, scalable model for eulerian spray modeling, International Journal of Multiphase Flow, vol. 83, pp. 162 - 171, 2016.

[39] Pandal, A., Pastor, J. M., Payri, R., Kastengren, A., Duke, D., Matusik, K., Giraldo, J. S., Powell, C., and Schmidt, D., Computational and experimental investigation of interfacial area in near-field diesel spray simulation, SAE Int. J. Fuels Lubr., vol. 10, 2017.

[40] Pandal, A., Payri, R., García-Oliver, J., and Pastor, J., Optimization of spray break-up CFD simulations by combining $\Sigma-Y$ eulerian atomization model with a response surface methodology under diesel engine-like conditions (ECN Spray A), Computers \& Fluids, vol. 156, pp. 9 - 20, 2017.

[41] Payri, R., García, J., Salvador, F., and Gimeno, J., Using spray momentum flux measurements to understand the influence of diesel nozzle geometry on spray characteristics, Fuel, vol. 84, no. 5, pp. 551 - 561, 2005. 
[42] Payri, R., García-Oliver, J. M., Xuan, T., and Bardi, M., A study on diesel spray tip penetration and radial expansion under reacting conditions, Applied Thermal Engineering, vol. 90, pp. 619 - 629, 2015.

[43] Payri, R., Ruiz, S., Gimeno, J., and Martí-Aldaraví, P., Verification of a new CFD compressible segregated and multi-phase solver with different flux updates-equations sequences, Applied Mathematical Modelling, vol. 39, no. 2, pp. $851-861,2015$.

[44] Pei, Y., Hawkes, E. R., Bolla, M., Kook, S., Goldin, G. M., Yang, Y., Pope, S. B., and Som, S., An analysis of the structure of an n-dodecane spray flame using $\{$ TPDF $\}$ modelling, Combustion and Flame, vol. 168, pp. $420-435$, 2016 .

[45] Pei, Y., Hawkes, E. R., Kook, S., Goldin, G. M., and Lu, T., Modelling n-dodecane spray and combustion with the transported probability density function method, Combustion and Flame, vol. 162, no. 5, pp. 2006 - 2019, 2015 .

[46] Peters, N., Laminar diffusion flamelet models in non-premixed turbulent combustion, Progress in Energy and Combustion Science, vol. 10, no. 3, pp. 319 - 339, 1984.

[47] Pitzer, K. S., Lippmann, D. Z., Jr., R. F. C., Huggins, C. M., and Petersen, D. E., The volumetric and thermodynamic properties of fluids. ii. compressibility factor, vapor pressure and entropy of vaporization1, Journal of the American Chemical Society, vol. 77, no. 13, pp. 3433-3440, 1955.

[48] Pope, S., An explanation of the turbulent round-jet/plane-jet anomaly, AIAA, vol. 16, pp. 279-281, 1978.

[49] Pope, S., Pdf methods for turbulent reactive flows, Progress in Energy and Combustion Science, vol. 11, no. 2, pp. 119 - 192, 1985.

[50] Reid, R., Prausnitz, J., and Poling, B., The Properties of Gases and Liquids, McGraw-Hill, 1987.

[51] Ricou, F. P. and Spalding, D. B., Measurements of entrainment by axisymmetrical turbulent jets, Journal of Fluid Mechanics, vol. 11, no. 1, p. 21-32, 1961.

[52] Sallam, K. A. and Faeth, G. M., Surface properties during primary breakup of turbulent liquid jets in still air, AIAA Journal, vol. 41, no. 8, pp. 1514-1524, 2003. 
[53] Salvador, F., Gimeno, J., Pastor, J., and Martí-Aldaraví, P., Effect of turbulence model and inlet boundary condition on the diesel spray behavior simulated by an eulerian spray atomization (ESA) model, International Journal of Multiphase Flow, vol. 65, pp. 108-116, 2014.

[54] Siebers, D., Liquid-phase fuel penetration in diesel sprays, Trans. SAE, vol. 107, pp. 1205-1227, 1998.

[55] Siebers, D., Scaling liquid-phase fuel penetration in diesel sprays based on mixing-limited vaporization, Trans. SAE, vol. 108, pp. 703-728, 1999.

[56] Siebers, D. L., 2008. Recent developments on diesel fuel jets under quiescent conditions, Flow and combustion in reciprocating engines. Arcoumanis, C. and Kamimoto, T. (Eds.). Springer-Verlag, Berlin, pp. 257-308.

[57] Tillou, J., Michel, J., Angelberger, C., Bekdemir, C., and Veynante, D., Largeeddy simulation of diesel spray combustion with exhaust gas recirculation, Oil Gas Sci. Technol. - Rev. IFP Energies nouvelles, vol. 69, no. 1, pp. 155-165, 2014.

[58] Tillou, J., Michel, J.-B., Angelberger, C., and Veynante, D., Assessing LES models based on tabulated chemistry for the simulation of diesel spray combustion, Combustion and Flame, vol. 161, no. 2, pp. 525 - 540, 2014.

[59] Trask, N., Schmidt, D., Lightfoot, M., and Danczyk, S., Compressible modeling of the internal flow in a gas-centered swirl-coaxial fuel injector, Journal of Propulsion and Power, vol. 28(4), pp. 685-693, 2012.

[60] Vallet, A. and Borghi, R., Modélisation Eulerienne de l'atomisation d'un jet liquide, C.R. Acad. Sci, Paris, vol. 327, pp. 1015-1020, 1999.

[61] Vallet, A., Burluka, A., and Borghi, R., Development of a Eulerian model for the "atomization" of a liquid jet, Atomization and Sprays, vol. 11, pp. 619-642, 2001.

[62] Wang, H., Ra, Y., Jia, M., and Reitz, R. D., Development of a reduced ndodecane-pah mechanism and its application for n-dodecane soot predictions, Fuel, vol. 136, pp. 25 - 36, 2014.

[63] Wang, Y., Lee, W., Reitz, R., and Diwakar, R., Numerical simulation of diesel sprays using an eulerian-lagrangian spray and atomization (ELSA) model coupled with nozzle flow, SAE Technical Paper 2011-01-0386, 2011. 
[64] Weller, H., Tabor, G., Jasak, H., and Fureby, C., A tensorial approach to computational continuum mechanics using object-oriented techniques, Computers in Physics, vol. 12, pp. 620-631, 1998.

[65] Winklinger, J., Implementation of a Combustion Model based on the Flamelet Concept and its Application to turbulent reactive Sprays, PhD thesis, Departamento de Máquinas y Motores Térmicos, Universidad Politécnica de Valencia, España, 2014.

[66] Xue, Q., Battistoni, M., Powell, C., Longman, D., Quan, S., Pomraning, E., Senecal, P., Schmidt, D., and Som, S., An eulerian CFD model and x-ray radiography for coupled nozzle flow and spray in internal combustion engines, International Journal of Multiphase Flow, vol. 70, no. 0, pp. 77 - 88, 2015.

[67] Xue, Q., Battistoni, M., Som, S., Quan, S., Senecal, P. K., Pomraning, E., and Schmidt, D. P., Eulerian cfd modeling of coupled nozzle flow and spray with validation against x-ray radiography data, SAE Int. J. Engines, vol. 7(2), pp. 1061-1072, 2014. 